\title{
Occurrence of non-volant mammals on islands along the Kimberley coast of Western Australia
}

\author{
L.A. Gibson and N.L. McKenzie \\ Department of Environment and Conservation, Science Division, \\ PO Box 51, Wanneroo, Western Australia 6946, Australia. \\ Email: Lesley.Gibson@dec.wa.gov.au
}

\begin{abstract}
The inshore islands of the northern Kimberley are relatively un-altered examples of the adjacent mainland's substrates and vegetation communities. Being naturally sheltered from many anthropogenic disturbances evident on the mainland, these islands are likely to be important refuges for mammals. A systematic survey of 24 of the largest islands along the northern Kimberley coast revealed the presence of 18 non-volant mammal species (19 species are now known from these islands), most of which fall within the 'critical weight range' of $35 \mathrm{~g}-5.5 \mathrm{~kg}$. We recorded previously undetected species on a number of islands including two new island populations of each of the threatened species Dasyurus hallucatus, Isoodon auratus and Mesembriomys macrurus, and one new population of the Kimberley endemic Zyzomys woodwardi. The persistence of two other Kimberley endemics on the islands, Petrogale burbidgei and Wyulda squamicaudata was also confirmed. Small mammals $(\leq 35 \mathrm{~g})$ were rarely detected on the islands, with only two small rodents recorded (Pseudomys nanus and $P$. delicatulus). The most important factor determining mammal species richness was island area, closely followed by distance to the mainland, then proximity to a river mouth. Species composition was related to presence of preferred mainland habitats.
\end{abstract}

KEYWORDS: biological survey, critical weight range mammals, island biogeography, island conservation

\section{INTRODUCTION}

The sensitivity of Australian mammals to human-associated disturbance has been well documented and is highlighted by a rapid loss of species since European settlement (e.g. Burbidge and McKenzie 1989; Johnson 2006; McKenzie et al. 2007). These losses have been most pronounced in the arid and semi-arid areas of central Australia, and appear to be size-dependent, with the most severely affected group comprising mediumsized mammals (i.e. 'critical weight range' [CWR] of $35 \mathrm{~g}-5.5 \mathrm{~kg}$ ) (Burbidge and McKenzie 1989). In contrast, the high rainfall zones of northern Australia have been considered resilient to humaninduced disturbances, although there is evidence of more recent mammal declines occurring here as well (Woinarski et al. 2001, 2010, 2011a, 2011b; Burbidge et al. 2008). Mammal declines have been recorded in the drier southern and eastern parts of the Kimberley in Western Australia (e.g. Start et al. 2011), but the fauna of its high rainfall north-western parts is reported to be intact with no mammal extinctions evident (McKenzie et al. 2007; Start et al. 2007; Burbidge et al. 2008). The Kimberley's three endemic non-volant mammal species (Petrogale burbidgei, Wyulda squamicaudata and Zyzomys woodwardi) are now largely restricted to the high rainfall north-west, and distributions of several other medium-sized mammals have also contracted to this area (Burbidge et al. 2008). However, as the threatening processes likely to be responsible for overall biodiversity loss in the southern and eastern Kimberley (Gibson and McKenzie 2012) now pervade the entire Kimberley, increasing concern has been expressed regarding the stability of its mammal populations (Lochman and Lochman 2003; Start et al. 2007; Legge et al. 2011). Moreover, the recent invasion of the introduced Cane Toad (Rhinella marina) into the east Kimberley is likely to pose an added threat to susceptible fauna, particularly carnivorous mammals, as it expands westwards across the region (How et al. 2009; Shine 2010).

The importance of islands in terms of biodiversity conservation has long been recognised, especially because they have been naturally sheltered from many mainland disturbances (e.g. Burbidge et al. 1997; Woinarski et al. 2001, 2011a). There is also greater scope for their protection from intrusions of exotic species and frequent fires. According to 


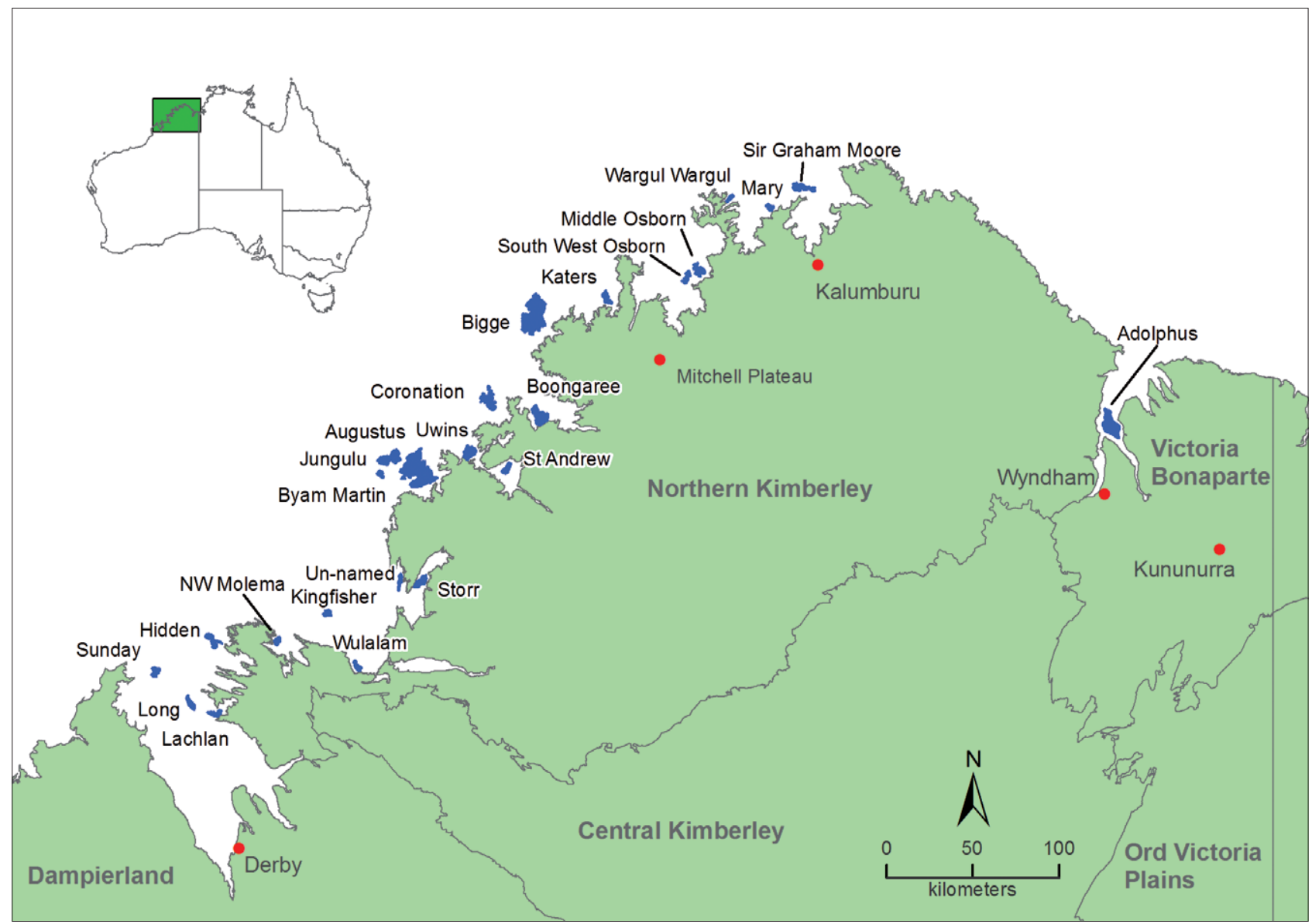

FIGURE 1

Geographic location of islands sampled (in blue for clarity) along the Kimberley coast of Australia. The biogeographic regions are also shown.

Burbidge et al. (2008), eight species that were once widely distributed on the Australian mainland are now restricted to offshore islands. A further 10 mammals classified as either endangered or vulnerable on the mainland, also have island populations (Burbidge et al. 1997). The extensive archipelagos and island groups located off the northern Kimberley coast collectively support representative examples of most of the substrates and vegetation communities found on the adjacent mainland (Burbidge and McKenzie 1978). As such, they are likely to be important refuges for mammals. Formed by rising sea levels at the end of the last Pleistocene glaciation, these islands have been isolated from the mainland for up to 10,000 years (Nix and Kalma 1972; How et al. 2006).

To date, published accounts of the mammal fauna on islands off the Kimberley coast have focused on the Bonaparte Archipelago and island groups in the northwest of the region (see Burbidge and McKenzie 1978; How et al. 2006; Start et al. 2007). A biological survey of the Kimberley rainforests also documented mammals on a small number of islands in the north (see Friend et al. 1991). Brief surveys of islands in the
Buccaneer Archipelago further south were carried out in 1982 and, although not formally published, mammal occurrences on these islands were catalogued by Abbott and Burbidge (1995) in a database that includes all known information from Australian islands. In addition, McKenzie et al. (1995) documented the mammal fauna of another island in the Buccaneer group (Koolan). According to these surveys, all mammal species present on the islands are known from the adjacent north-west Kimberley mainland, although the island list is relatively poor in species.

Here, we report the results of surveys for non-volant mammals (i.e. excluding bats) on 24 Northern Kimberley islands carried out between 2007 and 2010, and then compile all mammal records available from the islands. We were not only interested in determining island locations of mammal species, but also the potential factors influencing their richness and composition among islands. We investigate the species-area relationship for non-volant mammals to determine if larger islands support a higher diversity of mammals, as expected for insular populations (e.g. Burbidge et al. 1997; Woinarski et al. 1999, 2011a), as well as 
the relationship between mammal diversity and island isolation. The results are discussed in terms of the significance of the islands for mammal conservation.

\section{METHODS}

\section{THE ISLANDS}

We selected 24 of the largest islands (Figure 1), targeting those with a variety of geological surfaces, as well as ensuring geographic coverage from north to south, and varying distance from the mainland. The basis of this selection was twofold: first, to locate islands of high biodiversity value (e.g. supporting threatened taxa), and second, to collectively encompass the region's environmental diversity. The range of islands chosen extends from Sir Graham Moore Island off the Anjo Peninsula in the north to Sunday Island off Cape Leveque in the south-west, and to Adolphus Island in the Cambridge Gulf in the east. Islands from the Bonaparte and Buccaneer Archipelagos, as well as several other island groups are included (Figure 1). Islands sampled for the first time include Adolphus, Mary, Wargul Wargul, an un-named island adjacent to Lizard Island (called Un-named here), Storr, another un-named island in Talbot Bay (called NW Molema here) and Wulalam.

Geological and vegetation descriptions of the islands are given in Gibson and McKenzie (2012). Briefly, sandstone and volcanic strata structure the island landscapes (Table 1). The sandstones tend to give rise to rugged, dissected terrains, while the volcanics usually produce a more rounded and gently undulating topography (Burbidge and McKenzie 1978). Tertiary duricrusts occur as mesas and dissected tablelands on some islands, capping volcanic, sandstone or doleritic strata. Broad vegetation communities on the islands include tropical savannas, hummock grassland, rainforest, coastal tussock grassland, riparian paperbark woodlands and mangroves (Burbidge and McKenzie 1978).

The area experiences two distinct seasons, a 'dry' season extending from around May to November, and a 'wet' season from December to April when the majority of rain falls. Cyclonic activity is also a feature of the climate here. Average annual rainfall ranges from $>1500 \mathrm{~mm}$ at Mitchell Plateau to $<800$ $\mathrm{mm}$ at Cape Leveque (http://www.bom.gov.au). Temperatures are mild to hot throughout the year, with high relative humidity peaking during the wet season.

\section{SAMPLING}

Campsites on the islands were selected using local knowledge, inspection of satellite imagery and a reconnaissance flight. A number of alternative campsites were presented to the Traditional Owners for their consideration so as to avoid culturally sensitive areas. The aim was to place survey teams within walking distance of as many habitat/vegetation types as possible. In the dry season, campsites were accessed by helicopter, so final selection was made as the helicopter approached the site and found a safe landing site. Two campsites were usually needed to access the environmental variation of the largest islands (Table 1). All sampled sites were revisited in the wet season except for Mary and Wargul Wargul, where time constraints precluded sampling. A combination of a charter boat and helicopter was used during the wet season. In total, 31 campsites were sampled over four dry and three wet seasons from 2007 to 2010 (Table 1).

During the dry season, three or four transect lines were established within walking distance of the campsite. Each consisted of alternating medium Elliott traps $(33 \times 10 \times 10 \mathrm{~cm})$, large Elliott traps $(50 \times$ $17 \times 17 \mathrm{~cm}$ ) and collapsible Tomahawk cage traps (51 $x 18 \times 18 \mathrm{~cm}$ ), with each trap being approximately 10 $\mathrm{m}$ apart. Transect lines were positioned to sample the major habitat types of the island. For the first dry season survey in 2007, the combination of traps per transect line was 15 medium Elliotts, 12 large Elliotts and 10 cages. During the second trip in 2008 (and in 2010), the trap configuration was 15 medium Elliotts, 17 large Elliotts and five cages per transect. The arrangement was again altered in 2009 with 15 medium Elliotts, 10 large Elliotts and five cages. Traps were baited with a mixture of peanut butter and rolled oats, and set for either four or five consecutive nights (see Table 1 for total trap nights per island). In addition, each transect was searched during the day and at night (by spotlight), and sightings or signs of presence (i.e. scats and tracks) were also recorded. In addition, hair contained in predator scats was identified. During the wet season surveys, each transect was searched for a single day and night, with mammal sightings or sign recorded. For a select number of sites, a limited number of medium Elliott traps were set for a single night in an effort to capture animals observed during the dry season but not trapped.

\section{DATA ANALYSIS}

We selected a number of covariates that have been shown to influence species richness of mammals on islands (e.g. Burbidge et al. 1997; Woinarski et al. 1999) (Table 2). These include island size, distance to the mainland, annual rainfall, maximum elevation of an island and proximity to a major river mouth. We defined island size as the area of land mass (ha) that was unlikely to be inundated (i.e. tidal mudflats and mangroves were excluded), and was 
TABLE 1 Kimberley islands selected for survey including their area, the year/s (dry/wet season) sampled, surface geology (minor) and total trap effort (including the number of base camps, the number of nights sampled, the number of transect lines sampled and total trap nights for each island).

Geology codes: Qc - Quaternary coastal mudflats (excluding mangroves), Qs - Quaternary (beach) sand, Qa - Quaternary non-saline clay, Czs - Cenozoic sediments, Pkp - Pentecost sandstone, Pkb - Pentecost sandstone (Buckland Point Member), Pkw - Warton sandstone, Pkl - King Leopold sandstone, Pky - Pentecost sandstone (Yampi Member), Pkc - Carson volcanics, Pdh - Hart dolerite, Tp - Tertiary laterite, Pke - Elgee siltstone, Tb - Tertiary bauxite

\begin{tabular}{|c|c|c|c|c|c|c|c|}
\hline Island & $\begin{array}{l}\text { Area } \\
\text { (ha) }\end{array}$ & Year & Geology & $\begin{array}{l}\text { No. } \\
\text { Campsites } \\
\end{array}$ & Nights & Transects & $\begin{array}{l}\text { Trap } \\
\text { nights }\end{array}$ \\
\hline Adolphus & 4134 & $2008 / 9$ & Qc, Pkp & 2 & 10 & 8 & 2960 \\
\hline Augustus & 18929 & $2008 / 9$ & Pkw (Pkc, Czs, Qc, Qa) & 2 & 8 & 8 & 2368 \\
\hline Bigge & 17108 & $2007 / 8$ & Pkl (Pdh, Czs, Qs, Qc) & 2 & 10 & 8 & 2960 \\
\hline Boongaree & 4164 & $2007 / 9$ & $\operatorname{Pkl}$ (Pdh, Qc, Qs) & 1 & 5 & 4 & 740 \\
\hline Byam Martin & 816 & $2008 / 9$ & Pkw (Pkb) & 1 & 4 & 3 & 444 \\
\hline Coronation & 3791 & $2008 / 9$ & Pkc (Pkl, Czb, Qs, Qc) & 2 & 8 & 8 & 2368 \\
\hline Hidden & 1871 & 2009/10 & $\operatorname{Pkl}(\mathrm{Qc}, \mathrm{Qs})$ & 1 & 4 & 4 & 480 \\
\hline Jungulu & 4803 & 2008/9 & Pkw (Qa, Qs) & 2 & 8 & 8 & 2368 \\
\hline Katers & 1713 & 2009/10 & Pkl (Pdh, Qs) & 1 & 5 & 4 & 740 \\
\hline Kingfisher & 300 & 2009/10 & Pky (Qc) & 1 & 4 & 4 & 480 \\
\hline Lachlan & 1150 & $2009 / 10$ & Pkl (Pdh) & 1 & 4 & 4 & 480 \\
\hline Long & 1125 & $2009 / 10$ & $\mathrm{Pkl}(\mathrm{Qc})$ & 1 & 4 & 3 & 444 \\
\hline Mary & 847 & 2010 & Czs (Pkl, Qs, Qa, Qc) & 1 & 4 & 4 & 592 \\
\hline Middle Osborn & 2378 & $2007 / 8$ & Pkc (Tp, Qs) & 2 & 10 & 8 & 2960 \\
\hline NW Molema & 592 & $2009 / 10$ & Pkp (Pke, Pkw, Qc, Qa) & 1 & 4 & 4 & 480 \\
\hline $\begin{array}{l}\text { Sir Graham } \\
\text { Moore }\end{array}$ & 2812 & $2007 / 8$ & Tp (Pkl, Qs, Qa, Qc) & 2 & 10 & 8 & 1147 \\
\hline St Andrew & 1465 & 2008/9 & $\mathrm{Pkc}(\mathrm{Pkw})$ & 1 & 4 & 4 & 592 \\
\hline Storr & 1883 & 2009/10 & $\mathrm{Pkl}(\mathrm{Qc}, \mathrm{Qa})$ & 1 & 4 & 4 & 480 \\
\hline Sunday & 1186 & 2009/10 & Pkl (Qc, Qs) & 1 & 4 & 3 & 444 \\
\hline $\begin{array}{l}\text { South West } \\
\text { Osborn }\end{array}$ & 1340 & $2007 / 8$ & Pkc (Pkw, Qs) & 1 & 5 & 3 & 555 \\
\hline Un-named & 897 & 2009/10 & Pkp (Pkb, Qc, Qs) & 1 & 4 & 4 & 480 \\
\hline Uwins & 3219 & $2008 / 9$ & Pkw (Qs) & 1 & 4 & 4 & 592 \\
\hline Wargul Wargul & 626 & 2010 & $\mathrm{~Tb}(\mathrm{Pkc}, \mathrm{Qs})$ & 1 & 5 & 4 & 740 \\
\hline Wulalam & 415 & 2009/10 & Pky & 1 & 5 & 4 & 740 \\
\hline
\end{tabular}


TABLE 2 Values of the variables used in species richness modelling of non-volant mammals on Kimberley islands. Key: Distance - distance to the mainland, Area - area of island, Elevation - maximum elevation, River mouth - proximity to river mouth (1-5 increasing distance from major river mouth), Rainfall - average annual rainfall.

\begin{tabular}{|c|c|c|c|c|c|}
\hline Island & Distance (km) & Area (ha) & Elevation (m) & Rivermouth & Rainfall (mm) \\
\hline Adolphus & 1.96 & 4134 & 244 & 1 & 827 \\
\hline Augustus & 1.79 & 18929 & 181 & 4 & 1170 \\
\hline Bigge & 2.97 & 17108 & 138 & 3 & 1103 \\
\hline Boongaree & 0.14 & 4164 & 235 & 2 & 1138 \\
\hline Byam Martin & 13.28 & 816 & 69 & 5 & 1144 \\
\hline Coronation & 6.07 & 3791 & 153 & 5 & 1141 \\
\hline Hidden & 1.48 & 1871 & 127 & 4 & 839 \\
\hline Jungulu & 18.91 & 4803 & 95 & 5 & 1148 \\
\hline Katers & 1.40 & 1713 & 101 & 4 & 1069 \\
\hline Kingfisher & 15.47 & 300 & 82 & 4 & 943 \\
\hline Lachlan & 0.17 & 1150 & 93 & 2 & 787 \\
\hline Long & 9.36 & 1125 & 65 & 2 & 768 \\
\hline Mary & 0.68 & 847 & 11 & 4 & 968 \\
\hline Middle Osborn & 2.34 & 2378 & 240 & 4 & 1051 \\
\hline NW Molema & 1.06 & 592 & 154 & 3 & 881 \\
\hline $\begin{array}{l}\text { Sir Graham } \\
\text { Moore }\end{array}$ & 2.84 & 2812 & 61 & 4 & 979 \\
\hline St Andrew & 2.23 & 1465 & 284 & 1 & 1127 \\
\hline Storr & 0.26 & 1883 & 165 & 1 & 1007 \\
\hline Sunday & 8.06 & 1186 & 59 & 3 & 778 \\
\hline $\begin{array}{l}\text { South West } \\
\text { Osborn }\end{array}$ & 3.07 & 1340 & 134 & 4 & 1041 \\
\hline Un-named & 0.69 & 897 & 83 & 3 & 1000 \\
\hline Uwins & 0.23 & 3219 & 134 & 2 & 1155 \\
\hline Wargul Wargul & 0.25 & 626 & 87 & 4 & 946 \\
\hline Wulalam & 0.86 & 415 & 77 & 2 & 901 \\
\hline
\end{tabular}

determined from digitised 1:100,000 topographic maps. Maximum elevation (m) was also extracted from the 1:100,000 topographic maps. Distance to the mainland $(\mathrm{km})$ was estimated using Google Earth $^{\mathrm{TM}}$ imagery. Average annual rainfall $(\mathrm{mm})$ was derived using the BIOCLIM module of ANUCLIM (Houlder et al. 2000). Using ArcMap GIS (ESRI Inc., Redlands, California, U.S.A.), rainfall values were extracted for each site sampled on an island as well as either four (one-site islands) or six (two-site islands) additional random sites across the islands and averaged for each island. A categorical measure of position of an island with respect to a river mouth was visually estimated from Google Earth ${ }^{\mathrm{TM}}$ to represent the likelihood of animals rafting/ swimming to the islands from the mainland (1-5 
represents decreasing likelihood). Pairwise Pearson correlations among all candidate variables revealed no strong inter-correlations (i.e. <0.8).

The number of native mammal species per island, collated from all available sources for each of the sampled islands (i.e. including those species undetected in the current survey), was used in the analysis. Hydromys chrysogaster was excluded from all analyses because absences were believed to be survey artifacts. The association between mammal species richness and all possible subsets of the five predictor variables (described above) was modelled by using a generalised linear model (GLM), assuming a Poisson distribution. Island size and distance to the mainland was log-transformed prior to analysis. Possible curvilinear relationships were first examined by preliminary inspection of response curves after fitting univariate GAMs (see Wintle et al. 2005). As mostly linear relationships were observed, and given the limited range in species richness per island, the use of GLM was considered appropriate compared to techniques that fit more complex relationships. Model selection was based on the second-order Akaike Information Criterion (AIC) (Burnham and Anderson 2002). We included all models in the final candidate set for model averaging, where inference is based on a set of plausible models, rather than a single model, to estimate parameters. We also calculated AIC weights $\left(w_{i}\right)$ and used these to weight model coefficients. The relative importance of covariates was examined by summing the $\mathrm{AIC}$ weights for each covariate across all models that it occurred in (w+; Burnham and Anderson 2002). Data analyses were run in the $\mathrm{R}$ statistical computing language ( $\mathrm{R}$ Development Core Team 2009) using algorithms to calculate the AIC values and standard errors. We evaluated the performance of the model-averaged model by regressing the fitted values against observed species richness values.

Species were clustered according to their cooccurrences on the same islands (presence-absence data) using the analysis package PATN (Belbin 1995). Byam Martin was excluded because $H$. chrysogaster is the only non-volant mammal known there, and the 'small Petrogale' on Jungulu was assumed to be the same as on its counterpart, Augustus, the next shoreward island in the chain (Petrogale concinna). The association measure 'Two-step' (Belbin 1980) was used to determine the quantitative relationship between each pair of species. The dimensionality of the species dissimilarity matrix was reduced using Semistrong Hybrid scaling (with 100 iterations, a minimum stress differential of 0.005 , and 100 random starts) and displayed as a three dimensional scatterplot with a superimposed Minimum Spanning Tree. Correlations with species attributes were determined by principal axis correlation analysis and significance assessed using Monte-Carlo simulation involving 1,000 randomisations of the regional vector scores. Species attributes assessed included substrate preference, whether the species' original geographical range was restricted to high rainfall regions or extended into more arid regions as well, vegetation/habitat preference and shelter type (Table 3). Their biological relevance for northern Australian mammals has been well documented (e.g. Friend et al. 1991; Burbidge and Manly 2002; Burbidge et al. 2008; Van Dyck and Strahan 2008). Overt patterns in the ordination scatterplot were also assessed extrinsically, in terms of the known habitat associations of component species throughout their geographical ranges (e.g. Van Dyck and Strahan 2008).

\section{RESULTS}

In total, 19 non-volant mammal species are now known from the 24 islands sampled (18 of these species were detected during the current survey) (Table 4). Overall trap success for those species caught in either large or medium Elliott traps or cages is shown in Table 5. The use of the three trap types was justified, and reflects the range in body mass of the mammals captured (Table 5). Total trap success of individual species on each island is shown in Appendix 1. Species that we detected but did not trap include Tachyglossus aculeatus (detected by scats and a single sighting), Macropus agilis (sightings), Hydromys chrysogaster (scats and tracks), Isoodon macrourus (sightings) and Petaurus breviceps (sightings). A small macropod (probably a rock wallaby) was briefly sighted on Jungulu Island, and scats were collected, but this animal remains unidentified. The two small rock wallabies Petrogale burbidgei and P. concinna were also difficult to capture in traps and many records consisted of sightings (some photographed). Additionally, an arboreal rodent was seen on Uwins Island. While this was thought to be Melomys burtoni, as this species has not previously been recorded on Uwins, a positive record requires further confirmation. A small dasyurid skull was found in leaf litter on NW Molema, but was mislaid.

We recorded previously undetected mammal species on a number of islands (Table 4). New to the Kimberley islands as a whole included Pseudomys nanus on Adolphus Island, Sminthopsis virginiae on Sir Graham Moore Island and M. agilis on Mary and Adolphus Islands, the latter two species being new records on Western Australian islands. All three species commonly occur on the adjacent mainland, with distributions that extend across much of northern Australia (Menkhorst and Knight 2001). The threatened species Mesembriomys 
macrurus (Environment Protection and Biodiversity Conservation Act 1999 - EPBC Act) was recorded for the first time on Augustus and Lachlan Islands. Another threatened species, Isoodon auratus (EPBC Act), was detected for the first time on Lachlan and Storr Islands. The endangered Dasyurus hallucatus (EPBC Act) was recorded on seven islands, with newly discovered populations on Adolphus and Storr Islands. A northern Kimberley endemic Zyzomys woodwardi was also recorded for the first time on Storr Island. We confirmed the persistence of other northern Kimberley endemics: Wyulda squamicaudata on Bigge Island, and Petrogale burbidgei on Bigge, Boongaree and Katers Islands. Non-detections of species from islands we sampled where they had been previously recorded are Rattus tunneyi on St Andrew Island, Pseudantechinus ningbing on Augustus Island and M. burtoni and W. squamicaudata on Boongaree Island (although scats suspected to belong to W. squamicaudata were collected). Three of these species were last detected on these islands in the early 1970s (see Burbidge

TABLE 3 Values of species attributes used in the analysis of co-occurrence patterns of non-volant mammal species on the Kimberley islands.

\footnotetext{
b Shelter (shelter preference): 0 - on the ground; 1 - burrows; 2 - tree hollows; 3 - rock crevices/caves.

${ }^{a}$ Climate (driest edge of original range): 1 - high and moderate rainfall, semi-arid and arid regions; 2 - high and moderate rainfall and semiarid regions; 3 - high and moderate rainfall regions; 4 - restricted to high rainfall regions of Australia.

b Substrate preference (for foraging): 1 - soils only; 2 - rocks and soils; 3 - rocks only.

Vegetation (vegetation specificity): 0 - catholic; 1 - riparian/cracking clays; 2 - soil savanna; 3 - sandstone savanna; 4 - mangrove/rainforest.
}

\begin{tabular}{lllll} 
Species & Shelter & Climate & Substrate & Vegetation \\
\hline Dasyurus hallucatus & 3 & 2 & 3 & 2 \\
Isoodon auratus & 0 & 1 & 3 & 3 \\
Isoodon macrourus & 0 & 3 & 1 & 2 \\
Macropus agilis & 0 & 2 & 1 & 2 \\
Melomys burtoni & 2 & 2 & 2 & 4 \\
Mesembriomys macrurus & 2 & 2 & 3 & 4 \\
Petaurus breviceps & 2 & 3 & 2 & 3 \\
Petrogale burbidgei & 3 & 4 & 3 & 3 \\
Petrogale concinna & 3 & 3 & 3 & 3 \\
Pseudantechinus ningbing & 3 & 3 & 3 & 3 \\
Pseudomys delicatulus & 1 & 2 & 2 & 2 \\
Pseudomys nanus & 0 & 1 & 1 & 2 \\
Rattus tunneyi & 1 & 1 & 2 & 1 \\
Sminthopsis virginiae & 1 & 4 & 1 & 1 \\
Tachyglossus aculeatus & 1 & 1 & 2 & 0 \\
Wyulda squamicaudata & 3 & 4 & 3 & 3 \\
Zyzomys argurus & 3 & 1 & 3 & 3 \\
Zyzomys woodwardi & 3 & 4 & 3 & 4 \\
Hydromys chrysogaster & 1 & 3 & 3 & 3 \\
\hline
\end{tabular}




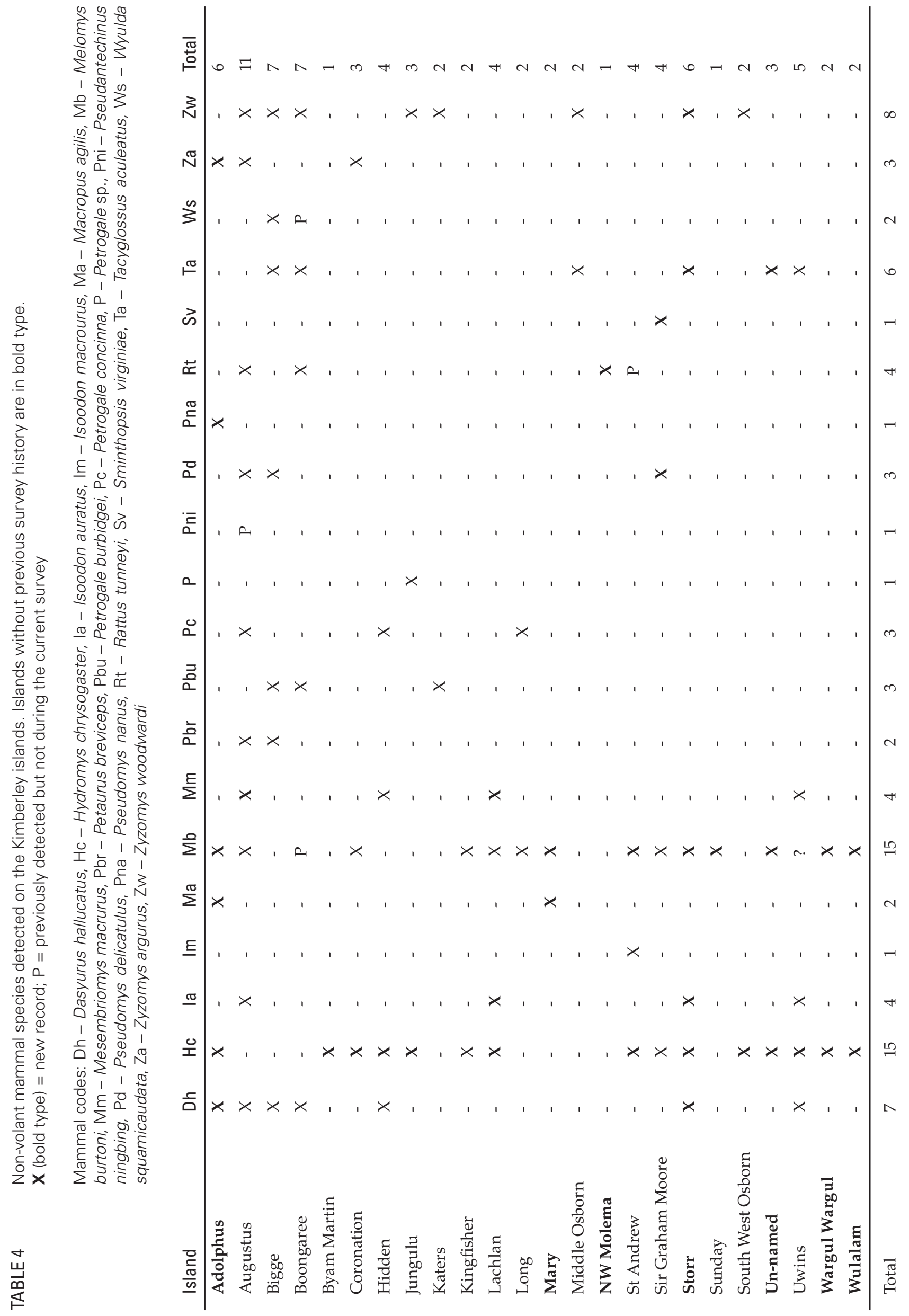


and McKenzie 1978). The exception is M. burtoni which was documented on Boongaree by both How et al. (2006) in 2005 and Start et al. (2007) in 2003-2004.

The most widespread species detected were $M$. burtoni and $H$. chrysogaster, both occurring on more than half of the islands sampled $(\mathrm{n}=15)$ (Table 4). The semi-aquatic H. chrysogaster (Water Rat) is likely to range widely among island groups, thereby making its detection on any single island variable. Zyzomys woodwardi was detected on eight islands, all with an estimated annual rainfall $>1,000 \mathrm{~mm}$ (Table 2). Dasyurus hallucatus tended to occur on the relatively large near-shore islands with all seven of them greater than 1,800 ha and less than $3 \mathrm{~km}$ from the mainland (Table 2). The remaining species were detected on only a few islands $(\leq 4)$ with the exception of T. aculeatus, present on six (Table 4). Although based on only a few occurrences, other species that were restricted to the high rainfall islands within the Bonaparte Archipelago include $P$. burbidgei and W. squamicaudata, both of which have distributions restricted to the north-west Kimberley. In contrast, P. concinna, M. macrurus and I. auratus also occurred on the lower rainfall islands of the Buccaneer Archipelago, further south.

The largest mammal detected on the islands was $M$. agilis (21 kg), occurring on Mary and Adolphus Islands. Both islands are close to the coast, particularly Mary Island which may be connected to the mainland at extreme low spring tides, thereby allowing passage of these wallabies from the mainland. There is also anecdotal evidence from Aboriginal informants of wallabies swimming to islands (T. Vigilante, pers. comm.). Small mammals ( $\leq 35 \mathrm{~g}$ ) were poorly represented on the islands, with only two small rodents detected (P. nanus and P. delicatulus on one and three islands, respectively). The majority of mammal species recorded fell within the critical weight range of 35 g-5.5 kg (Table 6).

Very few non-native species were recorded on the islands. Dog scats (possibly dingo Canis lupus dingo) were collected from Uwins Island and pig (Sus scrofa) diggings and wallows were observed on Sir Graham Moore Island.

The richness of non-volant mammals on islands was generally low, ranging from 1 to 11 (Table 4) with a mean of $3.5 \pm 0.5$ species per island. A maximum of 11 species was recorded on Augustus Island, the largest island sampled. An examination of the factors potentially influencing species richness on the sampled islands revealed that there was no clear best approximating model (i.e. $w_{\min } \geq 0.9$ ), and therefore the modelaveraging approach was appropriate. In Table 7, the top models are ranked according to their AIC differences $\left(\Delta_{i}\right)$, from best to worst. Model-averaged coefficients, unconditional standard errors and the sum of weights for models containing each candidate variable are shown in Table 8. In terms of explaining variation in species richness across all the islands sampled, the model-averaged model performed strongly (Adjusted $R^{2}=0.911, P<0.0001$ ). A positive association between species richness and island area and a negative association with distance to the mainland were both strongly supported, with 'area' occurring in all the top models $\left(w_{+}=\right.$ 1.00 and 0.69 , respectively). A negative association with proximity to river mouth was moderately supported $\left(w_{+}=0.44\right)$. There was only weak support for both a positive association with maximum elevation $\left(w_{+}=0.21\right)$ and negative association with annual average rainfall $\left(w_{+}=0.22\right)$, which was also reflected by the relatively high standard errors observed (Table 8). The importance of island area and distance to the mainland in influencing species richness is also indicated by the percent of deviance explained by the model containing both variables (85.1\%, Model 1, Table 7). Also, additional variables only marginally increased the percent of deviance explained (Table 7). The relationship between island area and species richness is shown in Figure 2.

When the retained species attributes were plotted as vectors into the scatterplot derived by ordinating species according to their co-occurrences on islands (Figure 3), they were near-orthogonal to one-another ( 3 -D divergence angle $=73^{\circ}$ ), implying independence, and tightly correlated with the observed co-occurrence pattern ('climatic envelope': $R^{2}=0.60,0.0 \%$ of randomisations exceeded this correlation value; 'substrate': $R^{2}=0.56,0.1 \%$ ). These correlations were unlikely to be an analysis artifact because multi-dimensional scaling of the species dissimilarity matrix to three dimensions did not result in high 'stress' (0.09).

By assigning transects to broad habitat types and examining mean abundances (i.e. number/transect) we attempted to characterise potential habitat preferences on the islands for each of the mammals recorded on the transect lines (exceptions were $I$. macrourus and P. breviceps with only one sighting on a transect and T. aculeatus with signs only) (Figure 4). Species mainly occurring in massive boulder country of dissected sandstone included $P$. burbidgei and $W$. squamicaudata. Other species also largely recorded in rocky habitats were I. auratus, P. concinna, Z. woodwardi and Z. argurus. Dasyurus hallucatus, P. delicatulus, M. macrurus and R. tunneyi occurred commonly along riparian habitats. Melomys burtoni was commonly recorded along mangrove edges and on sand plains. 
TABLE 5 Trap success per 100 trap nights of individual mammals caught in large Elliott traps (LE), medium Elliott traps (ME) and Tomahawk wire cage traps (MC) averaged across all the islands sampled. Number of trap nights divided by 100 for each trap method is shown in brackets.

\begin{tabular}{|c|c|c|c|c|}
\hline Species & Weight (g) & Trap type & Captures & $\begin{array}{l}\text { Captures/100 trap } \\
\text { nights }\end{array}$ \\
\hline \multirow[t]{3}{*}{ Wyulda squamicaudata } & 1650 & LE (103.5) & 3 & 0.03 \\
\hline & & ME (110.8) & 0 & 0.00 \\
\hline & & MC (49.1) & 9 & 0.18 \\
\hline \multirow[t]{3}{*}{ Petrogale concinna } & 1400 & $\mathrm{LE}$ & 1 & 0.01 \\
\hline & & ME & 0 & 0.00 \\
\hline & & $\mathrm{MC}$ & 0 & 0.00 \\
\hline \multirow[t]{3}{*}{ Petrogale burbidgei } & 1175 & LE & 4 & 0.04 \\
\hline & & ME & 1 & 0.01 \\
\hline & & $\mathrm{MC}$ & 6 & 0.12 \\
\hline \multirow[t]{3}{*}{ Dasyurus hallucatus } & 650 & $\mathrm{LE}$ & 20 & 0.19 \\
\hline & & ME & 8 & 0.07 \\
\hline & & $\mathrm{MC}$ & 22 & 0.45 \\
\hline \multirow[t]{3}{*}{ Isoodon auratus } & 450 & LE & 13 & 0.13 \\
\hline & & $\mathrm{ME}$ & 6 & 0.05 \\
\hline & & $\mathrm{MC}$ & 7 & 0.14 \\
\hline \multirow[t]{3}{*}{ Mesembriomys macrurus } & 280 & LE & 12 & 0.12 \\
\hline & & ME & 1 & 0.01 \\
\hline & & $\mathrm{MC}$ & 6 & 0.12 \\
\hline \multirow[t]{3}{*}{ Zyzomys woodwardi } & 145 & LE & 182 & 1.76 \\
\hline & & ME & 174 & 1.57 \\
\hline & & $\mathrm{MC}$ & 81 & 1.65 \\
\hline \multirow[t]{3}{*}{ Rattus tunneyi } & 130 & LE & 115 & 1.11 \\
\hline & & ME & 116 & 1.05 \\
\hline & & $\mathrm{MC}$ & 3 & 0.06 \\
\hline \multirow[t]{3}{*}{ Melomys burtoni } & 55 & LE & 200 & 1.93 \\
\hline & & ME & 265 & 2.39 \\
\hline & & $\mathrm{MC}$ & 11 & 0.22 \\
\hline \multirow[t]{3}{*}{ Zyzomys argurus } & 55 & LE & 28 & 0.27 \\
\hline & & ME & 40 & 0.36 \\
\hline & & $\mathrm{MC}$ & 1 & 0.02 \\
\hline \multirow[t]{3}{*}{ Sminthopsis virginae } & 46 & LE & 0 & 0.00 \\
\hline & & ME & 3 & 0.03 \\
\hline & & MC & 0 & 0.00 \\
\hline \multirow[t]{3}{*}{ Pseudomys nanus } & 35 & $\mathrm{LE}$ & 0 & 0.00 \\
\hline & & ME & 2 & 0.02 \\
\hline & & $\mathrm{MC}$ & 0 & 0.00 \\
\hline \multirow[t]{3}{*}{ Pseudomys delicatulus } & 9 & LE & 0 & 0.00 \\
\hline & & ME & 5 & 0.05 \\
\hline & & $\mathrm{MC}$ & 0 & 0.00 \\
\hline
\end{tabular}


TABLE $6 \quad$ Number of islands where each non-volant mammal species (collectively known from all Kimberley islands) was detected during the current survey. Average species weight (from Menkhorst and Knight 2001) and if this is within the critical weight range (CWR) is also shown.

\begin{tabular}{|c|c|c|c|c|c|}
\hline Species & Common name & Code & $\begin{array}{l}\text { No. Islands } \\
(n=24)\end{array}$ & Weight (g) & CWR \\
\hline \multicolumn{6}{|l|}{ Bandicoots } \\
\hline Isoodon auratus & Golden Bandicoot & Ia & 4 & 450 & $\mathrm{Y}$ \\
\hline Isoodon macrourus & $\begin{array}{l}\text { Northern Brown } \\
\text { Bandicoot }\end{array}$ & Im & 1 & 1750 & $\mathrm{Y}$ \\
\hline \multicolumn{6}{|l|}{ Dasyurids } \\
\hline Dasyurus hallucatus & Northern Quoll & Dh & 7 & 650 & $\mathrm{Y}$ \\
\hline Smithopsis virginiae & Red-cheeked Dunnart & Sv & 1 & 46 & $\mathrm{Y}$ \\
\hline Pseudantechinus ningbing & $\begin{array}{l}\text { Ningbing False } \\
\text { Antechinus }\end{array}$ & Pni & 0 & 24 & $\mathrm{~N}$ \\
\hline Planigale maculata & Common Planigale & Pm & 0 & 9 & $\mathrm{~N}$ \\
\hline \multicolumn{6}{|l|}{ Macropods } \\
\hline Macropus agilis & Agile Wallaby & Ma & 2 & $21 \mathrm{~kg}$ & $\mathrm{~N}$ \\
\hline Petrogale burbidgei & Monjon & $\mathrm{Pbu}$ & 3 & 1175 & $\mathrm{Y}$ \\
\hline Petrogale concinna & Narbelek & Pc & 3 & 1400 & Y \\
\hline Petrogale sp. & Rock wallaby & $\mathrm{P}$ & 1 & & \\
\hline \multicolumn{6}{|l|}{ Possums } \\
\hline Petrogale breviceps & Sugar Glider & $\mathrm{Pbr}$ & 2 & 120 & $\mathrm{Y}$ \\
\hline Wyulda squamicaudata & Scaly-tailed Possum & Ws & 1 & 1650 & Y \\
\hline \multicolumn{6}{|l|}{ Rodents } \\
\hline Hydromys chrysogaster & Water Rat & Hc & 15 & 700 & $\mathrm{Y}$ \\
\hline Melomys burtoni & Grassland Melomys & $\mathrm{Mb}$ & 14 & 55 & Y \\
\hline Mesembriomys macrurus & Golden-backed Tree Rat & $\mathrm{Mm}$ & 4 & 280 & Y \\
\hline Pseudomys delicatulus & Delicate mouse & $\mathrm{Pd}$ & 3 & 9 & $\mathrm{~N}$ \\
\hline Pseudomys nanus & Western Chestnut mouse & Pna & 1 & 35 & $\mathrm{Y}$ \\
\hline Rattus tunneyi & Pale Field Rat & Rt & 3 & 130 & Y \\
\hline Zyzomys argurus & Common Rock Rat & $\mathrm{Za}$ & 3 & 55 & $\mathrm{Y}$ \\
\hline Zyzomys woodwardi & Kimberley Rock Rat & $\mathrm{Zw}$ & 8 & 145 & Y \\
\hline \multicolumn{6}{|l|}{ Monotremes } \\
\hline Tachyglossus aculeatus & Echidna & Тa & 6 & 4500 & $\mathrm{Y}$ \\
\hline
\end{tabular}

\section{DISCUSSION}

The current survey added significant information regarding the location of non-volant mammal species on the inshore islands along the Kimberley coast. There are now 20 non-volant mammal species known to occur on all of the Kimberley islands with survey history (Appendix 2). While this richness is lower than the 33 species recorded on the adjacent mainland within the Northern Kimberley biogeographic region (Appendix 3), all three endemics, as well as 9 of the 13 species in the Northern Kimberley list that have suffered contractions in their wider geographical ranges in the Kimberley, are represented on the islands. While reduction in species diversity on islands 
TABLE 7 Results of $\mathrm{AlC}_{c}$-based model selection for the species richness of non-volant mammals on Kimberley islands (only top five models shown). Also shown are maximised log-likelihood function (log[L]), number of model parameters $(\mathrm{K}), \mathrm{AlC}_{c}$ differences $\left(\Delta_{i}\right)$, Akaike weights $\left(W_{i}\right)$ and percent of deviance explained by each model (\%Dev).

* Model includes variables: area - area of island (ha); dist - distance from mainland (km); river proximity to river mouth; rain - average annual rainfall (mm); elevation - maximum elevation (m).

\begin{tabular}{lcccccc} 
Model & $\log (\mathrm{L})$ & $K$ & $\mathrm{AIC}_{c}$ & $\Delta_{i}$ & $W_{i}$ & $\%$ DEV \\
\hline $\log ($ area $)+\log ($ dist $)$ & -35.33 & 3 & 77.87 & 0.00 & 0.286 & 85.1 \\
$\log ($ area $)+$ river & -35.95 & 3 & 79.10 & 1.24 & 0.154 & 82.2 \\
$\log ($ area $)+\log ($ dist $)+$ river & -34.60 & 4 & 79.31 & 1.45 & 0.139 & 88.5 \\
$\log ($ area $)+\log ($ dist $)+$ rain & -34.95 & 4 & 80.00 & 2.14 & 0.098 & 86.9 \\
$\log ($ area $)+\log ($ dist $)+$ elevation & -35.12 & 4 & 80.34 & 2.48 & 0.083 & 86.1 \\
\hline
\end{tabular}

TABLE 8

Model-averaged coefficients and unconditional standard errors for each variable included in the modelling of species richness of non-volant mammals on Kimberley islands. Sum of weights (i.e. relative importance) for models containing each coefficient $w_{+}$are also shown.

\begin{tabular}{llll} 
Variable & Coefficient & Standard Error & $W_{+}$ \\
\hline Constant & -3.3953 & 0.9605 & - \\
$\log ($ area $)$ & 1.4376 & 0.2796 & 1.00 \\
$\log ($ distance) & -0.3490 & 0.3017 & 0.69 \\
river & -0.0806 & 0.1205 & 0.44 \\
rain & -0.0001 & 0.0006 & 0.22 \\
elevation & 0.0003 & 0.0012 & 0.21 \\
\hline
\end{tabular}

isolated from much larger land masses is expected (Losos and Ricklefs 2010), it is also likely that some species were present but not detected. For example, the arboreal species Phascogale tapoatafa is difficult to detect and rarely trapped in the Northern Kimberley (Start et al. 2007). Species that have restricted distributions in the Kimberley in general and were not detected on the islands include Mesembriomys gouldii, Conilurus penicillatus, Trichosurus vulpecula and Petropseudes dahli, the latter species being restricted to particular rocky habitat types (McKenzie et al. 1975; Start et al. 2007; Webb et al. 2008). Tall open forests that contain hollow-bearing trees favoured by all these species (except P. dahli) (Friend et al. 1991; Woinarski et al. 1999) have a restricted distribution on the Kimberley islands, probably due to the mostly skeletal soils on the majority of the islands (Burbidge et al. 1991). Periodic cyclone damage to mature stands of trees may also reduce the availability of suitable refuges on the islands for these species. Another arboreal woodland species Petaurus breviceps was observed on only the two largest islands, both with relatively large areas of woodland.

Extensive grasslands associated with deep 
alluvial soils and/or heavy clay soils are collectively rare on the islands which may explain the present-day absence of the rodent Leggadina lakedownensis and the rarity of another small rodent Pseudomys nanus, the dasyurids Planigale maculata and Sminthopsis virginiae, and the bandicoot Isoodon macrourus (McKenzie et al. 1975; Bradley et al. 1987). Three of the four latter species were each detected on one island only during the current survey and $P$. nanus was only detected on an alluvial plain. The third, P. maculata has been detected on Koolan Island (Western Australian Museum records), an island not sampled by us. Additionally, unlike rodents, many small dasyurids tend to be difficult to capture in metal traps (Start et al. 2007) and this may also explain the non-detection of Pseudantechinus ningbing and P. maculata in the current survey. A further small rodent present on the Kimberley mainland but undetected on the islands was Pseudomys johnsoni. This species requires small pebbles for nesting material (Kerle and Ford 2008) and the geological surfaces, such as the siltstones (Pke), that give rise to this material occupy only a small proportion of two of the islands sampled (Un-named and NW Molema).

We recorded three of the seven macropods known from the Northern Kimberley mainland on the islands, Macropus agilis for the first time on two of them, although there were anecdotal reports of this species occurring on both (T. Vigilante, pers. comm.). Macropus agilis is also known to occur on Northern Territory and Queensland islands (Abbott and Burbidge 1995). Two of the macropods not detected by us, $M$. antilopinus and $M$. robustus, are unlikely to persist on islands due to their large body size (> $35 \mathrm{~kg}$ ) and the limited resources on islands (Main and Yadav 1971). However, M. robustus does occur on islands off the Pilbara coast of Western Australia (Abbott and Burbidge 1995), and there are reports of $M$. robustus swimming across a narrow channel from the mainland to Hidden Island in the Buccaneer Archipelago ( $T$. Vigilante, pers. comm.). We found no evidence of $M$. robustus on Hidden Island. The small rock wallabies Petrogale burbidgei and P. concinna were first recorded on a small number of rugged sandstone islands in the early 1970s and 1980s and their persistence on these islands was confirmed during our survey. They do not co-occur on the same island. The larger rock wallaby $P$. brachyotis, while widespread on the adjacent mainland and Northern Territory islands (Woinarski et al. 1999), is absent from the Kimberley islands despite the presence of suitable sandstone habitat (Eldridge and Telfer 2008). The remaining macropod species not recorded from the islands is Onychogalea unguifera which is rare in the Northern Kimberley, tending to prefer drier conditions further inland (Ingleby and Gordon 2008). Abbott (1980) hypothesised that islands occupied or visited by Aborigines in the north-west of Australia were lacking macropod species due to hunting and/or by dingoes they

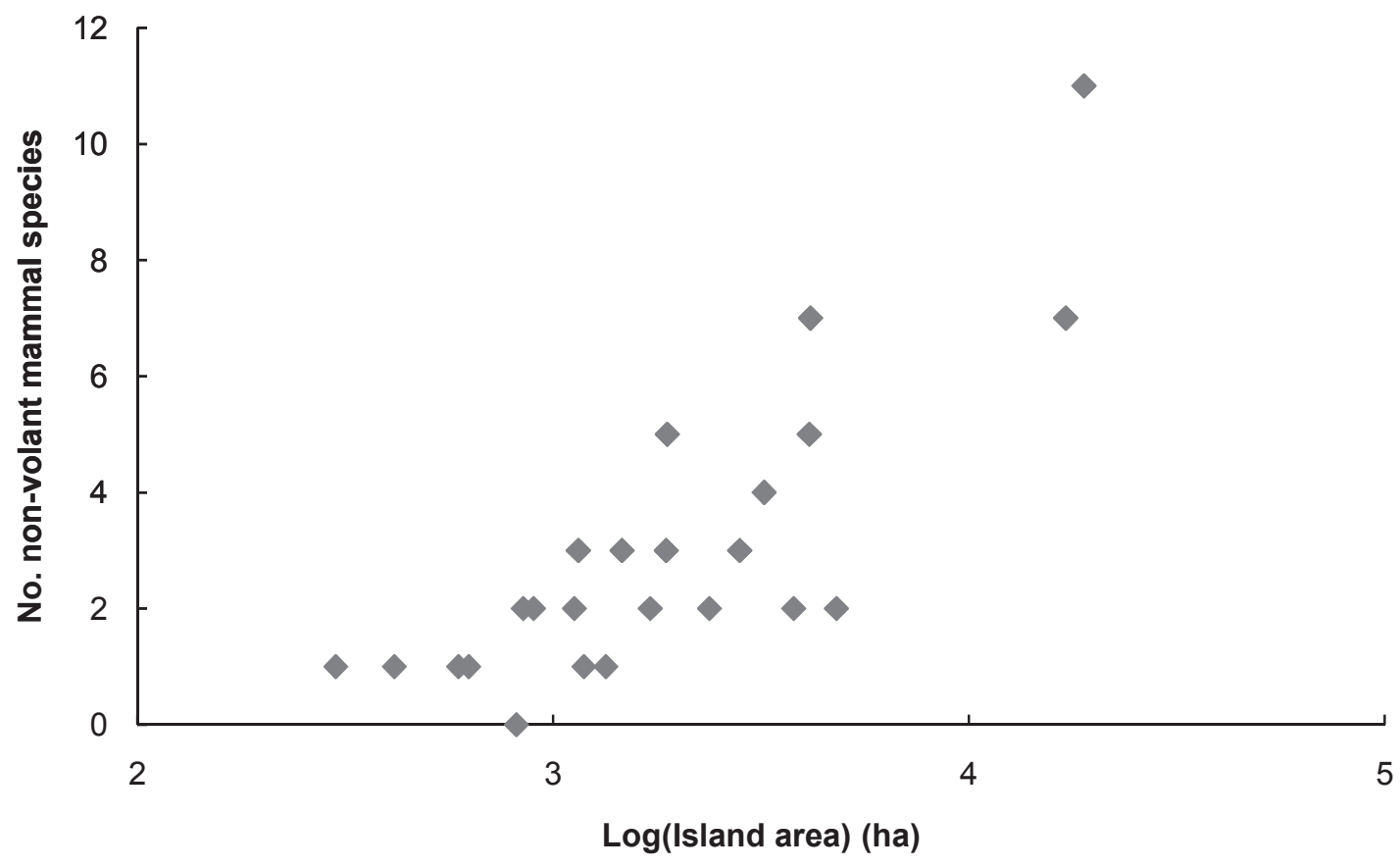

FIGURE 2 Island area v. richness of non-volant mammal species on the islands sampled in the Kimberley. 


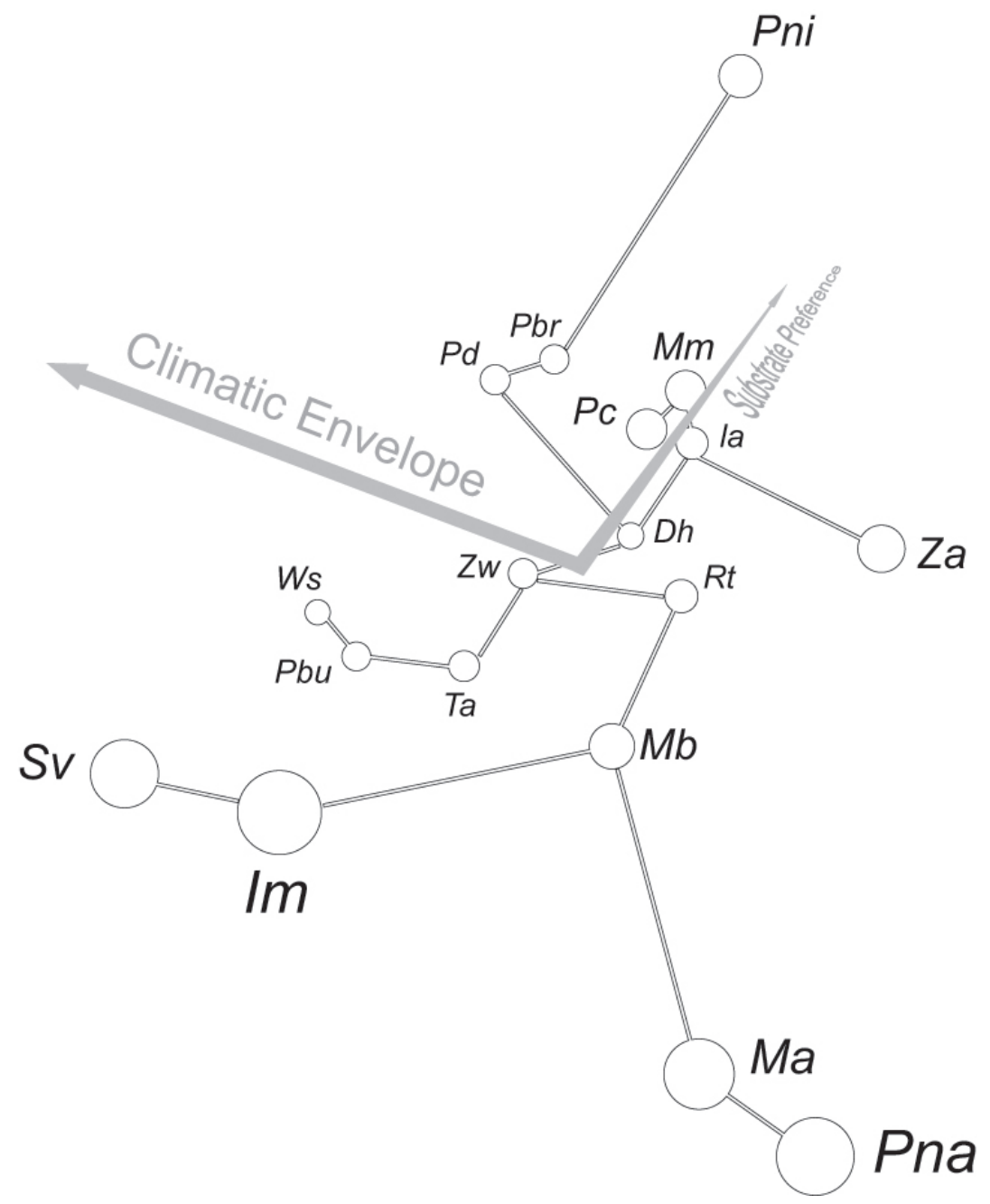

FIGURE 3 Three-dimensional ordination of the non-volant mammals according to their co-occurrences on the Kimberley islands (stress $=0.09$ ), with a superimposed Minimum Spanning Tree. Abbreviations: Dh Dasyurus hallucatus, Hc - Hydromys chrysogaster, la - Isoodon auratus, Im - Isoodon macrourus, Ma - Macropus agilis, Mb - Melomys burtoni, Mm - Mesembriomys macrurus, Pbr - Petaurus breviceps, Pbu - Petrogale burbidgei, Pc - Petrogale concinna, P - Petrogale sp., Pm - Planigale maculata, Pn Pseudantechinus ningbing, Pd - Pseudomys delicatulus, Pna - Pseudomys nanus, Rt - Rattus tunneyi, Sv - Sminthopsis virginiae, Ta - Tacyglossus aculeatus, Ws - Wyulda squamicaudata, Za - Zyzomys argurus, Zw - Zyzomys woodwardi.

introduced, as well as habitat alteration caused by Aboriginal use of fire on the islands.

The CWR mammals are well represented on the Kimberley islands with 17 of the 20 species present falling within the $35 \mathrm{~g}-5.5 \mathrm{~kg}$ range. Significantly, new populations of 11 CWR species were discovered on the islands during the current survey, including two new island populations of each of the threatened species Dasyurus hallucatus, Isoodon auratus and Mesembriomys macrurus, and one new population of a northern Kimberley endemic Zyzomys woodwardi. Both I. auratus and M. macrurus have distributions that have contracted to the northern Kimberley, with the exception of I. auratus on Marchinbar Island in the Northern Territory and on Barrow Island off the Pilbara coast of Western Australia (Abbott and Burbidge 1995). These two species are now known to co-occur on three Kimberley islands, Augustus, Lachlan and Uwins Islands. The surface geology of all three islands is predominantly dissected sandstone.

There are reports of a contraction in the distribution of Dasyurus hallucatus from the eastern and south-western Kimberley. It is not clear, 


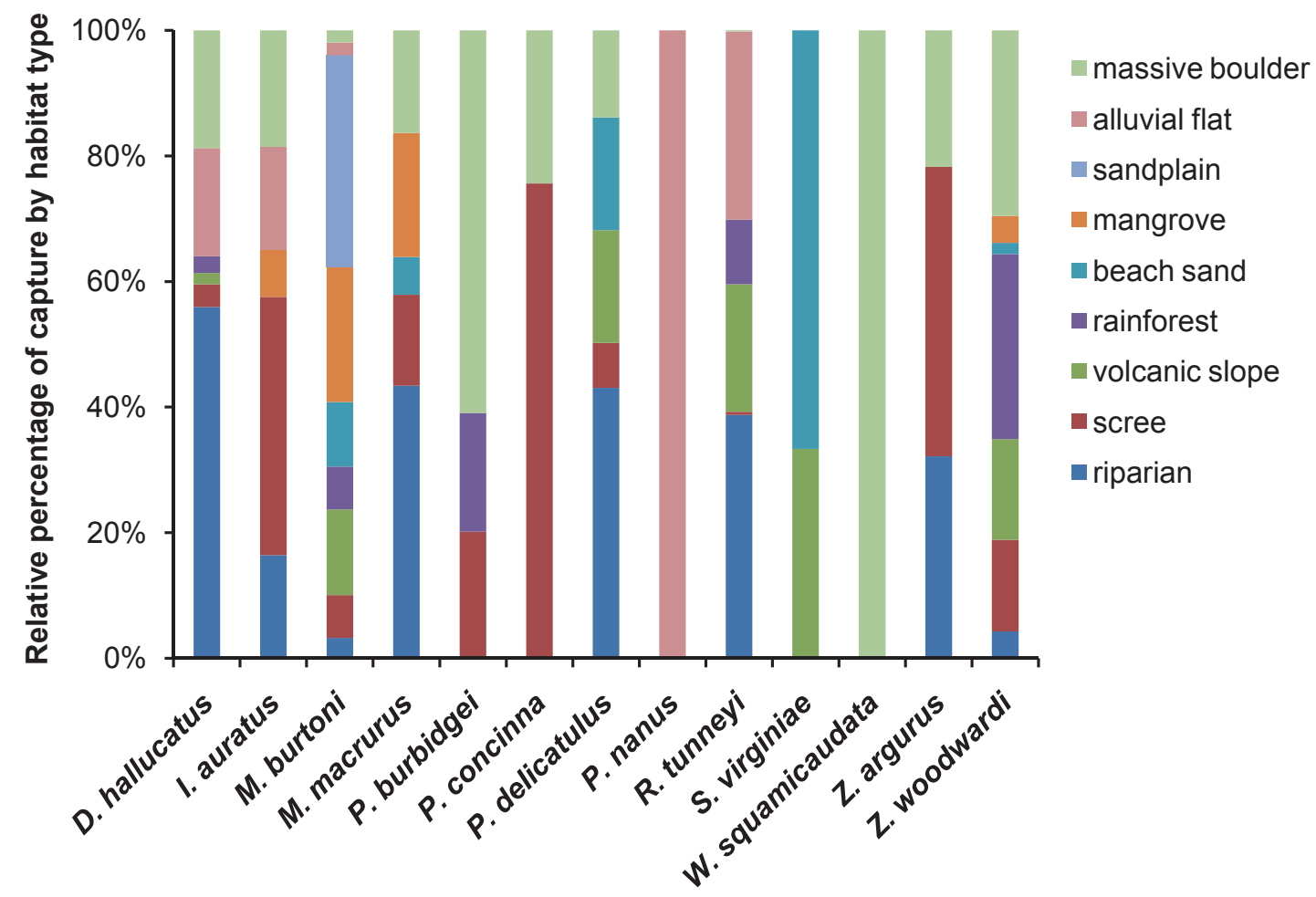

FIGURE $4 \quad$ Relative percentage of captures by habitat type of each non-volant mammal species on the Kimberley islands. Values have been corrected for the differential trapping effort in different habitat types.

however, if this is contraction is real or perceived due to a low species detection rate (How et al. 2009). Nevertheless, populations of D. hallucatus have declined elsewhere in Australia following the invasion of the poisonous Cane Toad, Rhinella marina (Shine 2010). The arrival of the Cane Toad into the Kimberley is also likely to have a significant impact on $D$. hallucatus in this region (How et al. 2009). The offshore islands may provide some refuge from Cane Toads, although those that are separated from the mainland by only a short distance and those located in close proximity to river mouths are likely to be susceptible to Cane Toad invasion. Cane Toads naturally colonised the Sir Edward Pellew island group in the Northern Territory following a major flooding event in 2001 (Woinarski et al. 2011a). The extirpation of D. hallucatus on one of those islands (Vanderlin) was closely linked to the arrival of Cane Toads on that island (Woinarski et al. 2011a). Prior to our survey, D. hallucatus was known from at least nine islands (records from Caffarelli, Carlia and Sir Frederick require further confirmation), and our two new discoveries on Adolphus and Storr increases the total to 11 islands (Appendix 2). Unfortunately, both of these islands are positioned in major river mouths and hence are at a high risk of Cane Toad invasion. How et al. (2009) also highlight the importance of these island populations as a potential source of founders for captive breeding and/or translocation should mainland populations of $D$. hallucatus collapse.

Populations of the three smaller carnivorous marsupials recorded on the Kimberley islands could also be affected by Cane Toads -- Sminthopsis virginiae (newly detected during our survey), Planigale maculata and Pseudantechinus ningbing. However, a captive study showed that $S$. virginiae and P. maculata learned to avoid Cane Toads after initial encounters (Webb et al. 2008; Shine 2010), and S. virginiae abundance did not vary at sites colonised by Cane Toads in Kakadu National Park, Northern Territory (Shine 2010).

Two of the 13 Northern Kimberley species that have suffered contractions of their wider distributions in the Kimberley are Rattus tunneyi and Isoodon macrourus (Burbidge et al. 2008). Rattus tunneyi has seen a decline of up to $90 \%$ of 
its former range and is now restricted to northern coastal Australia (Aplin et al. 2008). Disturbingly, Woinarski et al. (2010) also reported a marked localised decline in abundance of both $R$. tunneyi and I. macrourus in the tropics of the Northern Territory. However, these species do appear to be stable in the high rainfall zone of the Northern Kimberley (Start et al. 2007). We recorded $R$. tunneyi on three Kimberley islands (one a new island record), yet failed to detect it on a fourth island (St Andrew) from where it had been previously recorded (Table 4). This species is also known from a further two islands not sampled by us (Naturalists Island - Coate [2008], and an un-named island off Scott Strait - How et al. [2006]). They were caught in large numbers on Augustus, Bigge and Boongaree Islands ( $>70)$, while on NW Molema only seven captures were noted. It is likely that $R$. tunneyi experiences large fluctuations in abundance in response to climatic conditions (Aplin et al. 2008) and perhaps persists in lower numbers in areas of lower rainfall. This could explain the comparatively low number of detections on NW Molema. We recorded I. macrourus on St Andrew Island only, although a species of bandicoot has also been seen on the adjacent St Patrick Island (K. Coate, pers. comm.); its identity is yet to be confirmed. While only sighted by us, two specimens of I. macrourus were collected from St Andrew Island in the early 1970s (Burbidge and McKenzie 1978).

There has been some conjecture over the identity of a rock rat recorded on Coronation Island. Burbidge and McKenzie (1978) reported the animal to be a large form of $Z$. argurus (relative to mainland populations), while How et al. (2006) subsequently identified it as a small form of $Z$. woodwardi. Molecular analysis of the tissue extracted from individuals captured during the current survey confirmed them to be a large form of $Z$. argurus. This fits the 'island rule' of gigantism in smaller insular species (e.g. Lomolino 1985). While the generality of the island rule has been questioned, clade-specific patterns have been recognised; among them are the murid rodents which tend to increase in size on islands (Meiri et al. 2008).

Area was the most important factor determining species richness on the islands sampled, closely followed by distance to the mainland, with the larger islands and those closer to the mainland tending to support more mammal species. Burbidge et al. (1997) concluded that area was the sole factor influencing the richness of non-volant mammals on Australian islands. They did not, however, find a relationship between richness and distance to the mainland, and concluded that mammals on Australian islands are relictual rather than equilibrial faunas. Similarly, Woinarski et al. (1999) found little evidence to support a relationship between richness of mammals on the Northern Territory Arnhem Land islands and isolation variables. In our case, some of the islands we sampled were very close to the coast $(<300 \mathrm{~m})$, perhaps facilitating rafting and/or swimming to islands from the mainland by some mammals. The enormous tidal surges that occur in the Kimberley may also increase accessibility to the islands across shallow water and mud flats. Evidence for movement between the Kimberley mainland and islands is provided by the study of How et al. (2009). The genetic diversity of D. hallucatus populations on near-shore islands was more similar to the mainland than the islands separated by permanent sea channels, suggesting ongoing gene flow between the mainland and the islands close to the coast. In our study, islands in close proximity to river mouths were also likely to support a higher number of mammal species. During the wet season, and particularly after cyclones, a huge volume of water and associated debris is expelled from the catchments into the ocean, again facilitating movement of animals from the mainland to the islands.

Maximum elevation (a surrogate for habitat diversity) and average annual rainfall did not appear to be drivers of species richness in our case. Even so, rainfall does appear to influence the occurrence of some individual species on islands. For example, all the northern Kimberley endemics appear to be restricted to the high rainfall islands (although Z. woodwardi does occur on two islands with rainfall less than $1,000 \mathrm{~mm}$ ), while most others that have distributions (either current or historical) that extend outside this region, were also recorded on islands with rainfall less than $1,000 \mathrm{~mm}(P$. delicatulus and I. macrourus were the exceptions).

Some studies have indicated that species richness is largely a function of sampling effort, as found by Woinarski et al. (1999) on the Arnhem Land islands. We found a weak correlation between species richness and trap effort per island (Adjusted $R^{2}=$ $0.16, P<0.05)$ in our study. The new discoveries of mammal species previously undetected on the islands implies that some species are likely to be missed on the least visited islands. One potential 'false absence' is M. burtoni from Hidden, NW Molema and Uwins (although there was a likely sighting on the latter). NW Molema has extensive mangroves, a typical habitat of M. burtoni (Woinarski et al. 1999), but mangroves were not sampled on this island during our survey as they were too far from the campsite. Similarly, the mangroves fringing sections of Hidden Island were not sampled due to distance. Another species prone to false absences is $H$. chrysogaster. This species was only detected by scats and/or tracks on beaches. Therefore, where sampling sites were located 
inland, it was unlikely to be detected.

The compositional analysis revealed that the pattern of species co-occurrences on islands corresponds to the substrate preferences and climate envelopes of their mainland populations. Species to the left in the ordination plot (Figure 3) are confined to high rainfall areas whereas those to the right have (or had) extensive aridzone distributions; species in the foreground associate with soil substrates whereas those in the background are confined to outcrop country. This conclusion is best illustrated by the three rodents (M. burtoni, Z. woodwardi and R. tunneyi) that effectively dominate the data matrix (excluding $H$. chrysogaster), each of which has a distinct habitat association on the adjacent mainland (McKenzie et al. 1975; Bradley et al. 1987; Friend et al. 1991; Van Dyck and Strahan 2008). Melomys burtoni, a lithely-built arboreal rodent, is most commonly recorded in or immediately adjacent to mangrove and rainforest communities. Zyzomys woodwardi is largely restricted to rugged boulder country where its massive pelvic muscles are vital for efficient foraging, and $R$. tunneyi is found on substrates with deep soil such as river banks, valley floors, outwash plains and foot slopes, in which it can dig its extensive burrow systems. On the islands, $M$. burtoni was recorded on all those with large mangrove stands, but only on two of the eight islands with small mangrove patches (Appendix 4). All of the eight islands where $Z$. woodwardi was recorded contained areas of massive scree, and it was absent from all of the islands without massive scree (Appendix 4). Rattus tunneyi was only recorded on islands with areas of deep soil.

In terms of introduced mammal species, we found evidence (dry scats) of dingoes (Canis lupus dingo) on Uwins Island only, despite previous reports of this species on Augustus, Bigge, Middle Osborn and Wollaston Island (Burbidge and McKenzie 1978). However, the scats/tracks may have been left by domestic dogs accompanying human visitors. The introduced European rat Rattus rattus was recorded on Sunday Island in 1982, but there was no evidence of their presence during the current survey. However, the 1982 specimens were shot and not trapped, which may indicate that $R$. rattus are difficult to trap. This species has also been reported to occur on Long Island (Abbot and Burbidge 1995), but specimens lodged at the Western Australian Museum were subsequently found to be $M$. burtoni not $R$. rattus. Feral pigs (Sus scrofa) have been recorded on Sir Graham Moore Island (Burbidge and McKenzie 1978), and while signs of presence were observed during the dry season survey in August 2007, there was no fresh evidence of pigs during the subsequent wet season survey in February 2008. It is possible that increased water availability in the wet season allowed the pigs to move into another area on the island.

\section{CONSERVATION IMPLICATIONS}

With respect to the non-volant mammals, the islands of the Kimberley region in general are of high conservation value. These islands offer considerable protection from threatening processes contributing to the decline of many mammal species on the mainland, as well as the added threat of Cane Toad invasion. Given the positive relationship between island area and species richness, the larger islands (Augustus, Bigge, Boongaree and Adolphus) are of particular importance. Collectively, these four islands also support populations of all northern Kimberley endemics and eight species with contracted ranges on the mainland. Other islands such as Uwins, Lachlan, Hidden and Storr are important for their co-occurring threatened species and Katers Island for its two species endemic to the Kimberley region. St Andrew Island is also significant as it is the only island in the Kimberley known to have populations of both I. macrourus and R. tunneyi, species with contracting distributions on the mainland.

Fortunately, we found little evidence of introduced species on the Kimberley islands. However, a recent paper by Woinarski et al. (2011a) highlighted the susceptibility of islands to novel threats. The conservation significance of the Sir Edward Pellew island group in the Northern Territory has been lost mostly due to introductions of cats (Felis catus) and colonisation of Cane Toads (Woinarski et al. 2011a). Clearly, quarantine procedures and regular surveillance that help prevent the introduction and persistence of pest species on the Kimberley islands is critical.

\section{ACKNOWLEDGEMENTS}

The surveys involved many people and we wish to thank our colleagues from the Western Australian Department of Environment and Conservation (DEC), Western Australian Museum, Kimberley Land Council and Biota Environmental Sciences, the participating Traditional Owners, Aboriginal Rangers and base camp volunteers who contributed to the successful implementation of the field work. We thank the crew of MV Kimberley Escape, MV Odyssey and pilots from Heliwork and Broome Helicopters for transporting teams safely on and off islands. We are grateful to DEC regional staff from the Kununurra and Broome Districts for their support during the project. DEC staff based at the Mitchell River National Park provided valuable logistic support. The project was possible through a research agreement with the Kimberley Land Council for the Balanggarra, Bardi- 
Jawi, Dambimangari, Mayala and Uunguu native title claim groups. Thanks also to Russell Palmer, David Pearson, Tom Vigilante and two anonymous reviewers for comments on the manuscript. Funding was provided by the Natural Heritage Trust and DEC.

\section{REFERENCES}

Abbott, I. (1980). Aboriginal man as an exterminator of wallaby and kangaroo populations in islands round Australia. Oecologia 44: 347-354.

Abbott, I. and Burbidge, A.A. (1995). The occurrence of mammal species on the islands of Australia: a summary of existing knowledge. CALMScience $\mathbf{1}$ : 259-324.

Aplin, K., Braithwaite, R.W. and Baverstock, P.R. (2008). Pale Field-rat Rattus tunneyi Thomas 1904 (pp 698-700). In: Van Dyck, S. and Strahan, R. (eds), The mammals of Australia, third edition. Reed/New Holland: Sydney.

Belbin, L. (1980). TWOSTEP: a program incorporating asymmetric comparisons that uses two steps to produce a dissimilarity matrix. CSIRO Division of Land Use Research Technical Memorandum 80/9. CSIRO: Canberra.

Belbin, L. (1995). PATN Technical Reference. CSIRO Division of Wildlife and Ecology: Canberra.

Bradley, A.J., Kemper, C.M., Kitchener, D.J., Humphreys, W.F. and How, R.A. (1987). Small mammals of the Mitchell Plateau Region, Kimberley, Western Australia. Australian Wildlife Research 14: 397-413.

Burbidge, A.A. and Manly, B. (2002). Mammal extinctions on Australian islands: causes and conservation implications. Journal of Biogeography 29: 465-473.

Burbidge, A.A. and McKenzie, N.L. (1978). The islands of the north-west Kimberley: Western Australia. Wildlife Research Bulletin Western Australia No. 7. Department of Fisheries and Wildlife: Perth.

Burbidge, A.A. and McKenzie, N.L. (1989). Patterns in the modern decline of Western Australia's vertebrate fauna: causes and conservation implications. Biological Conservation 50: 143-198.

Burbidge, A.A., McKenzie, N.L., Brennan, K.E.C., Woinarski, J.C.Z., Dickman, C.R., Baynes, A., Gordon, G., Menkhorst, P.W. and Robinson, A.C. (2008). Conservation status and biogeography of Australia's terrestrial mammals. Australian Journal of Zoology 56: 411-422.

Burbidge, A.A, McKenzie, N.L. and Kenneally, K. (1991). Nature conservation reserves in the Kimberley, Western Australia. Department of Conservation and Land Management: Perth.

Burbidge, A.A., Williams, M.R. and Abbott, I. (1997). Mammals of Australian islands: factors influencing species richness. Journal of Biogeography 24: 703-715.

Burnham, K.P. and Anderson, D.R. (2002). Model selection and multimodel inference. A practical information-theoretic approach, second edition. Springer: New York.

Coate, K. (2008). Birds of Naturalist Island, Kimberley, Western Australia. Western Australian Naturalist 26: 73-84.

Eldridge, M.D.B. and Telfer, W.R. (2008). Short-eared
Rock-Wallaby Petrogale brachyotis Gould 1841 (pp 365-366. In: Van Dyck, S. and Strahan, R. (eds), The mammals of Australia, third edition. Reed/New Holland: Sydney.

Friend, G.R., Morris, K.D. and McKenzie, N.L. (1991). The mammal fauna of Kimberley rainforests (pp 393-412). In: McKenzie, N.L., Johnston, R.B. and Kendrick, P.G. (eds), Kimberley rainforests of Australia. Surrey Beatty \& Sons: Chipping Norton, Australia.

Gibson, L.A. and McKenzie, N.L. (2012). Identification of biodiversity assets of selected Kimberley islands: background and implementation. Records of the Western Australian Museum, Supplement 81: 1-14.

Houlder, D.J., Hutchinson, M.F., Nix, H.A. and McMahon, J.P. (2000). ANUCLIM user guide, version 5.1. Centre for Resource and Environmental Studies, Australian National University: Canberra.

How, R., Schmitt, L., Teale, R. and Cowan, M. (2006). Appraising vertebrate diversity of Bonaparte Islands, Kimberley, Western Australia. Western Australian Naturalist 25: 92-110.

How, R.A., Spencer, P.B.S. and Schmitt, L.H. (2009). Island populations have high conservation value for northern Australia's top marsupial predator ahead of a threatening process. Journal of Zoology 278: 206-217.

Ingleby, S. and Gordon, G. (2008). Northern Nailtail Wallaby Onychogalea unguifera Gould 1841 (pp 359-361). In: Van Dyck, S. and Strahan, R. (eds), The mammals of Australia, third edition. Reed/New Holland: Sydney.

Johnson, C. (2006). Australia's mammal extinctions: a 50000 year history. Cambridge University Press: Cambridge.

Kerle, J.A. and Ford, F. (2008). Kimberley Pebble-mouse Pseudomys johnsoni Kitchener, 1985 (pp 639-640), In: Van Dyck, S. and Strahan, R. (eds), The mammals of Australia, third edition. Reed/New Holland: Sydney.

Legge, S., Kennedy, M., Lloyd, R., Murphy, S. and Fisher, A. (2011). Rapid recovery of mammal fauna in the central Kimberley, northern Australia, following the removal of introduced herbivores. Austral Ecology 36: 791-799.

Lochman, J. and Lochman, M. (2003). Expressions of concern about the welfare of north-west Kimberley mammals. Wilderness News 163: 12-13.

Lomolino, M. (1985). Body size of mammals on islands: the island rule reexamined. American Naturalist 125: 310-316.

Losos, J.B. and Ricklefs, R.E. (2010). The theory of island biogeography revisited. Princeton University Press: Princeton, U.S.A.

Main, A. and Yadav, M. (1971). Conservation of macropods in reserves in Western Australia. Biological Conservation 3: 123-133.

McKenzie, N.L., Burbidge, A.A., Baynes, A., Brereton, R., Dickman, C.R., Gibson, L.A., Gordon, G., Menkhorst, R.W., Robinson, A.C., Williams, M.R. and Woinarski, J.C.Z. (2007). Analysis of factors implicated in the recent decline of Australia's mammalian fauna. Journal of Biogeography 34: 597-611.

McKenzie, N.L, Chapman, A. and Youngson, W.K. (1975). Mammals of the Prince Regent River Reserve, North-West Kimberley, Western Australia (pp 69-74). 
In: Miles, J.M. and Burbidge, A.A. (eds), A biological survey of the Prince Regent River Reserve, North-West Kimberley, Western Australia. Wildlife Research Bulletin Western Australia No 3. Department of Fisheries and Wildlife: Perth.

McKenzie, N.L., Fontanin, L., Lindus, N.V. and Williams, N.R. (1995). Biological inventory of Koolan Island, Western Australia. 2. Zoological notes. Records of the Western Australian Museum 17: 249-266.

Meiri, S., Cooper, N. and Purvis, A. (2008). The island rule: made to be broken? Proceedings of the Royal Society B 275: 141-148.

Menkhorst, P. and Knight, F. (2001). A field guide to the mammals of Australia. Oxford University Press: Melbourne.

Nix, H. and Kalma, J. (1972). Climate as a dominant control in the biogeography of northern Australia and New Guinea (pp 61-91). In: Walker, D. (ed.), Bridge and barrier: the natural and cultural history of Torres Strait. Research School of Pacific Studies Publication E6/3. Australian National University Press: Canberra.

R Development Core Team (2009). R: A language and environment for statistical computing. R Foundation for Statistical Computing: Vienna. URL: http://www.Rproject.org.

Ride, W.D. (1970). A guide to the native mammals of Australia. Oxford University Press: Melbourne.

Shine, R. (2010). The ecological impact of invasive Cane Toads (Bufo marinus) in Australia. The Quarterly Review of Biology 85: 253-291.

Start, A.N., Burbidge, A.A., McKenzie, N.L. and Palmer, C. (2007). The status of mammals in the north Kimberley, Western Australia. Australian Mammalogy 29: 1-16.

Start, A.N., Burbidge, A.A., McDowell, M.C. and McKenzie, N.L. (2011). The status of mammals along a rainfall gradient in the Kimberley, Western Australia. Australian Mammalogy, in press doi: 10.1071/AM10026.

Van Dyck, S. and Strahan, R. (eds) (2008). The mammals of
Australia, third edition. Reed/New Holland: Sydney.

Webb, J., Brown, G., Child, T., Greenlees, M., Phillips, B. and Shine, R. (2008). A native dasyurid predator (common planigale, Planigale maculata) rapidly learns to avoid a toxic invader. Austral Ecology 33: 821-829.

Wintle, B., Elith, J. and Potts, J. (2005). Fauna habitat modelling and mapping: a review and case study in the Lower Hunter Central Coast region of NSW. Austral Ecology 30: 719-738.

Woinarski, J.C.Z., Milne, D.J. and Wanganeen, G. (2001). Changes in mammal populations in relatively intact landscapes of Kakadu National Park, Northern Territory, Australia. Austral Ecology 26: 360-370.

Woinarski, J.C.Z., Palmer, C., Fisher, A., Southgate, R., Masters, P. and Brennan, K. (1999). Distributional patterning of mammals on the Wessel and English Company Islands, Arnhem Land, Northern Territory, Australia. Australian Journal of Zoology 47: 87-111.

Woinarski, J.C.Z., Armstrong, M., Brennan, K., Fisher, A., Griffiths, A.D., Hill, B., Milne, D.J., Palmer, C., Ward, S., Watson, M., Winderlich, S. and Young, S. (2010). Monitoring indicates rapid and severe decline of native small mammals in Kakadu National Park, northern Australia. Wildlife Research 37: 116-126.

Woinarski, J.C.Z., Ward, S., Mahney, T., Bradley, J., Brennan, K., Ziembicki, M. and Fisher, A. (2011a). The mammal fauna of the Sir Edward Pellew island group, Northern Territory, Australia: refuge and death-trap. Wildlife Research 38: 307-322.

Woinarski, J.C.Z., Legge, S., Fitzsimmons, J.A., Traill, B.J., Burbidge, A.A., Fisher, A., Firth, R.S.C., Gordon, I.J., Griffiths, A.D., Johnson, C., McKenzie, N.L., Palmer, C., Radford, I., Rankmore, B., Ritchie, E., Ward, S. and Ziembicki, M. (2011b). The disappearing mammal fauna of northern Australia: context, cause and response. Conservation Letters 4: 192-201.

MANUSCRIPT RECEIVED AUGUST 2011; ACCEPTED OCTOBER 2011. 


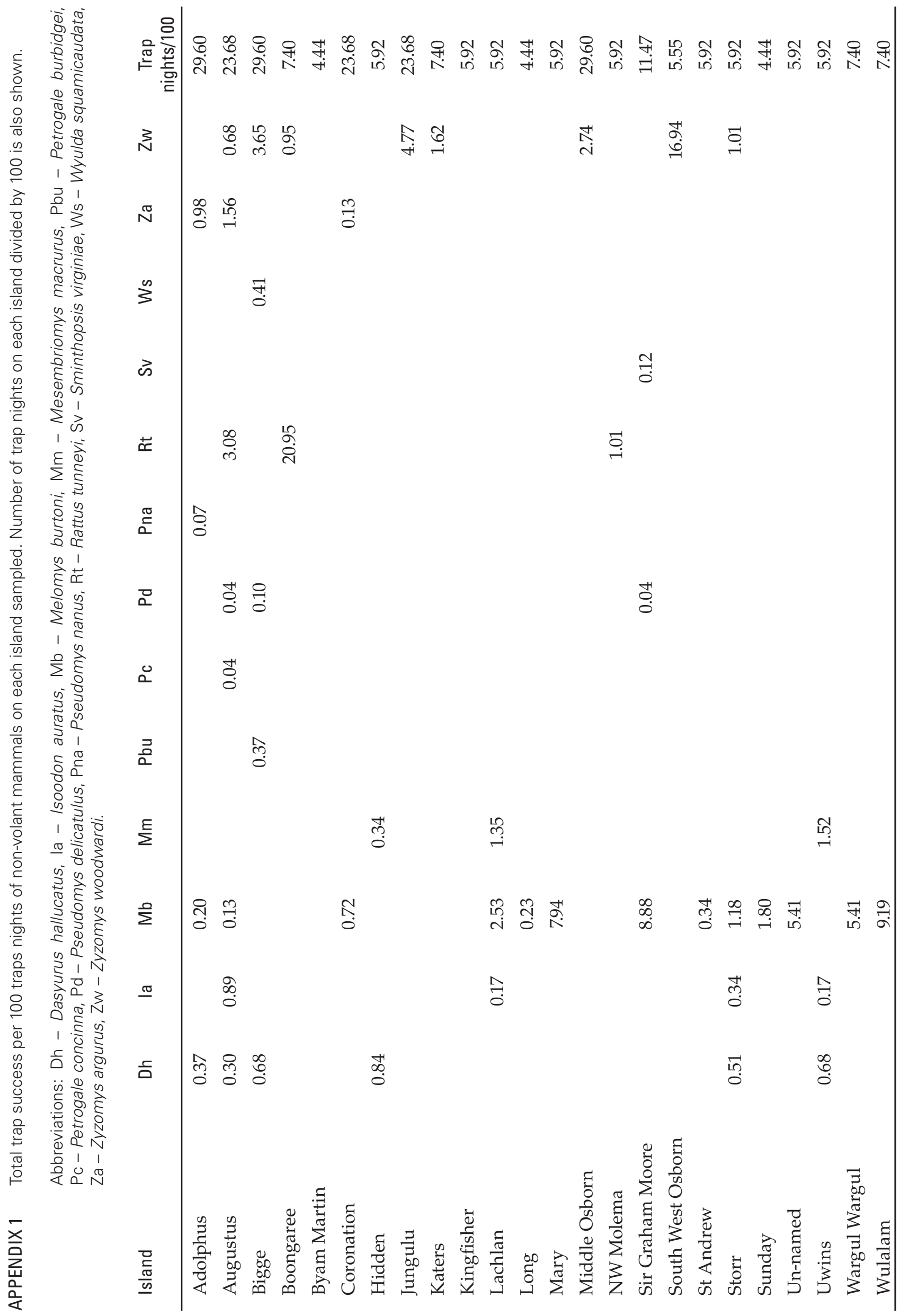




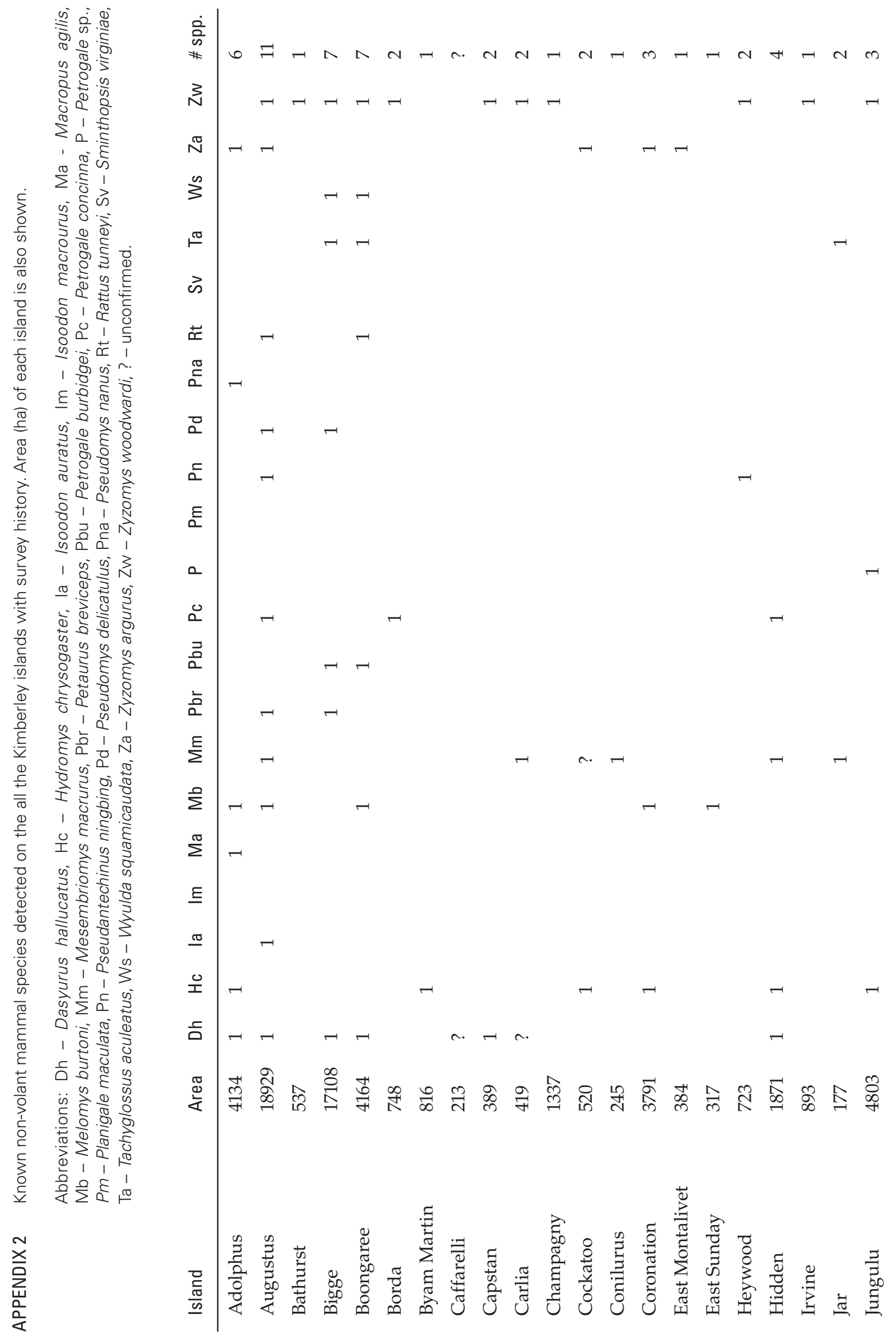




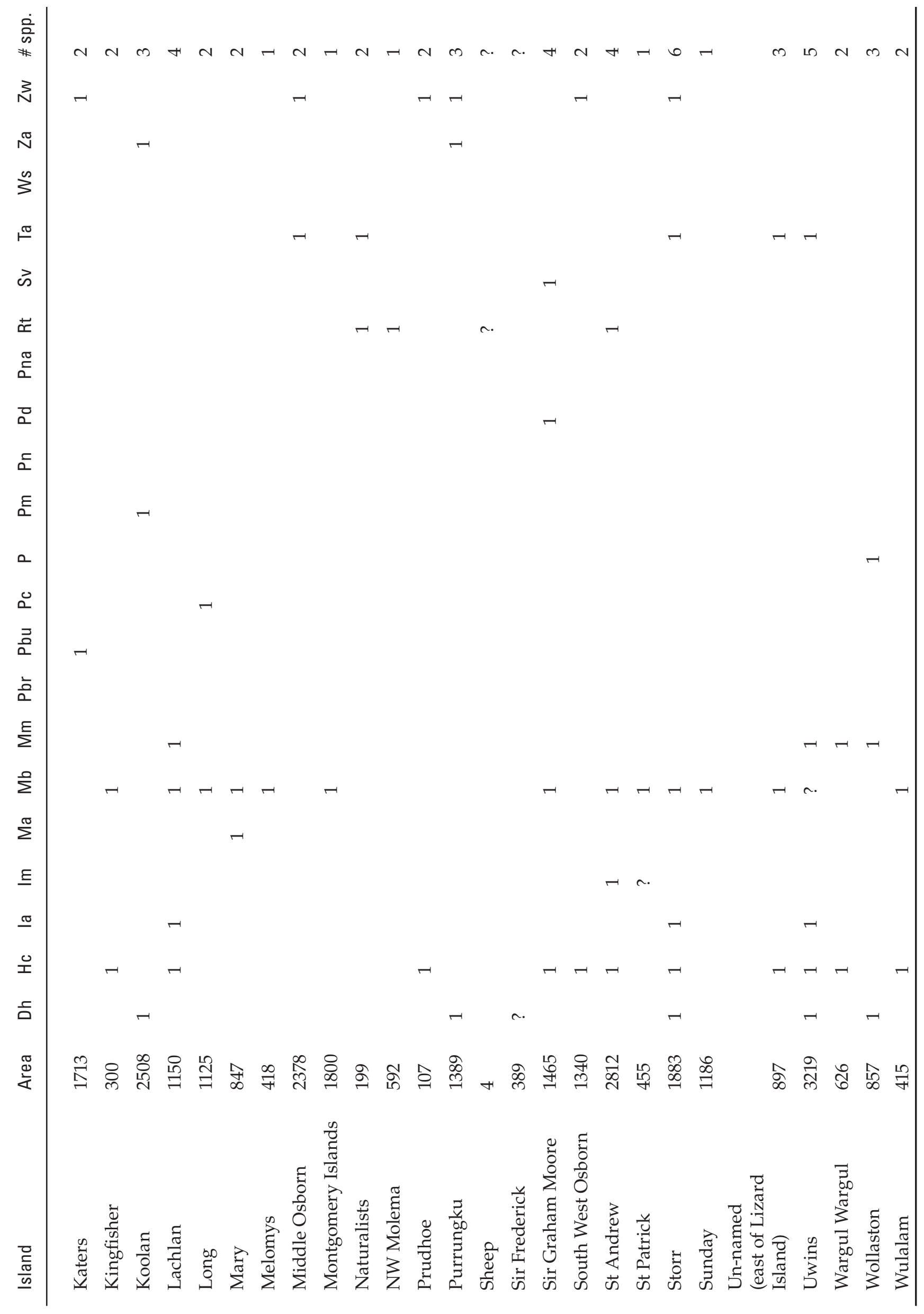




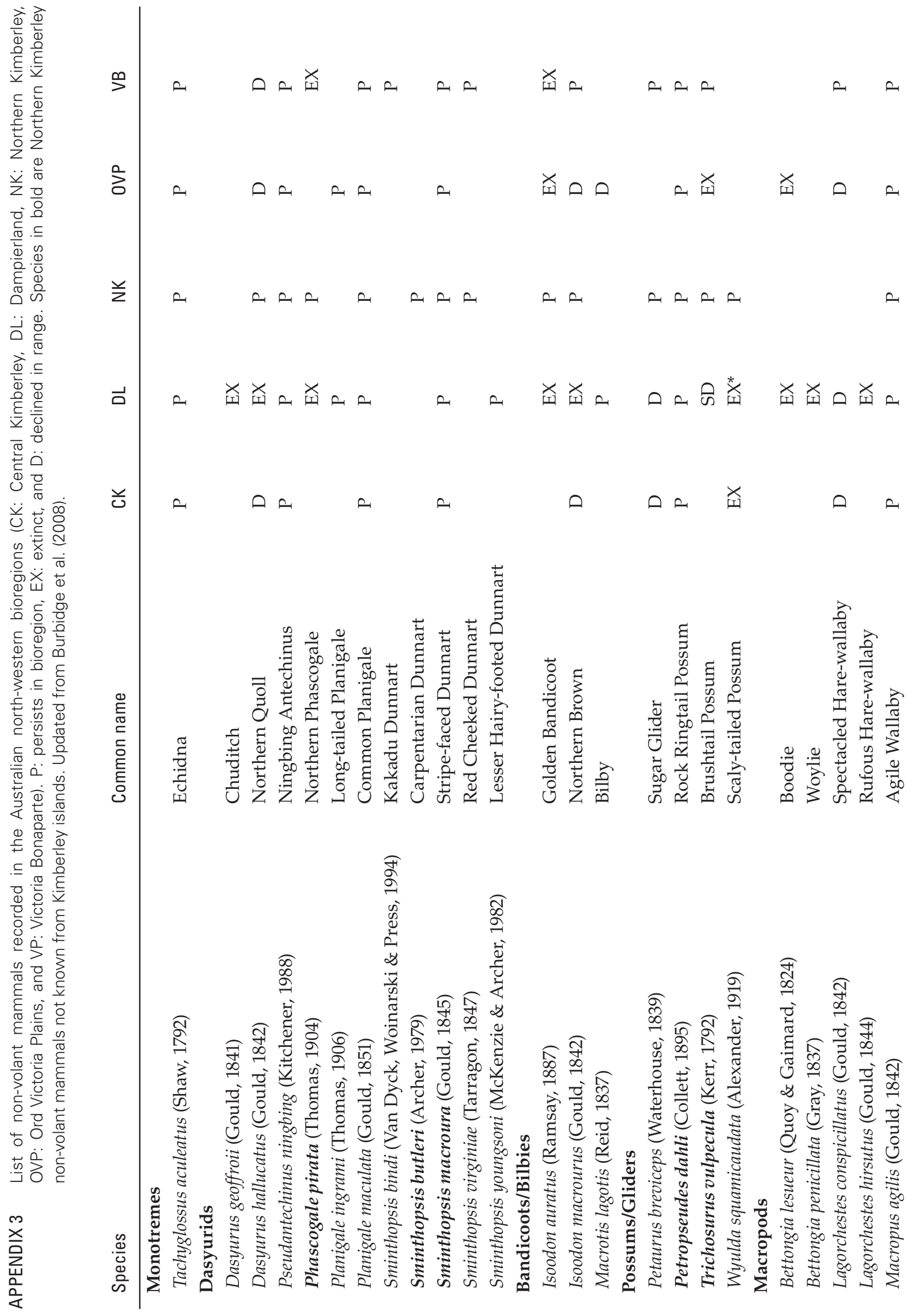




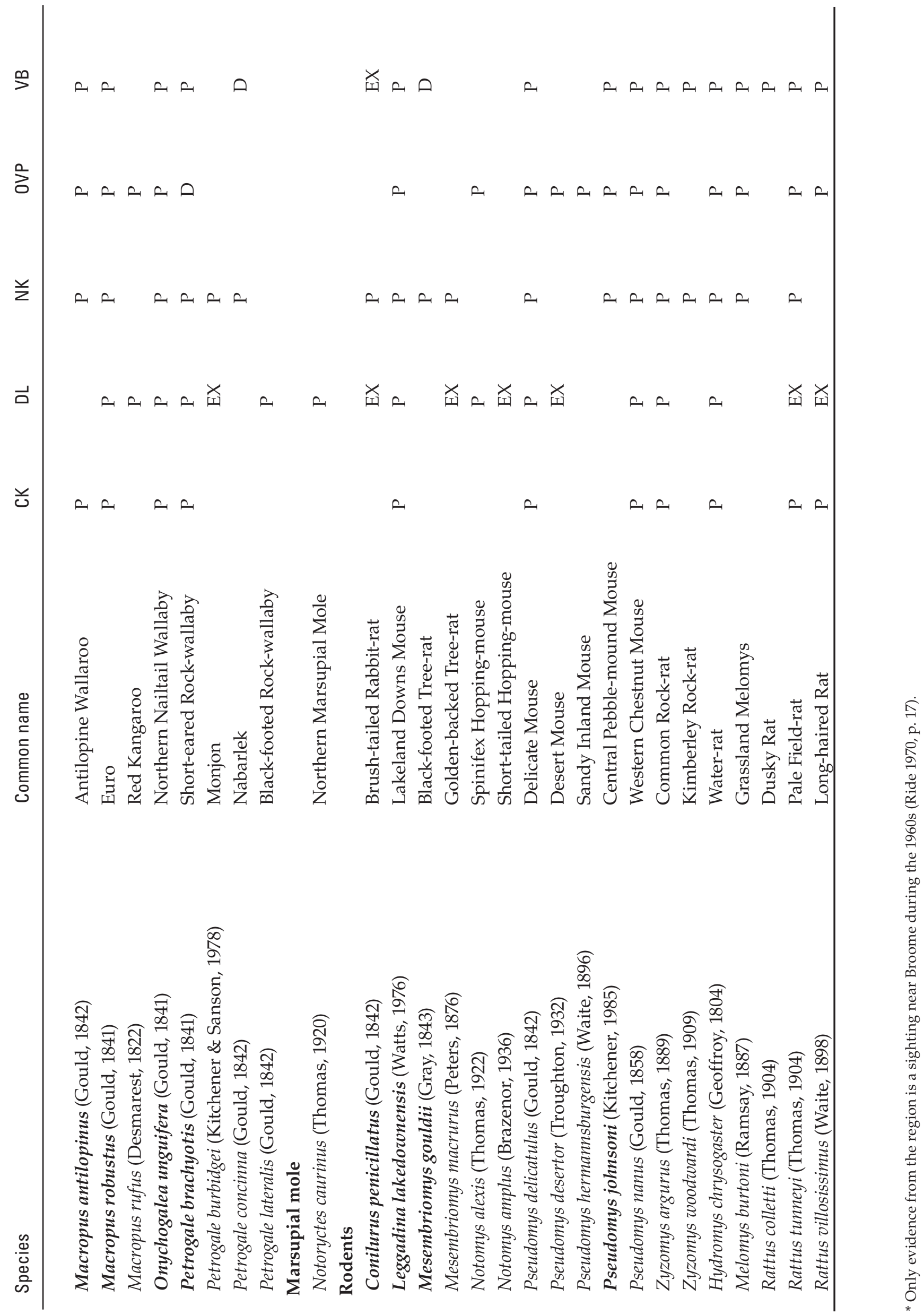


APPENDIX 4 Estimated extent of massive scree and mangroves on the Kimberley islands sampled.

\begin{tabular}{|c|c|c|c|}
\hline Island & $\begin{array}{l}\text { Area of massive } \\
\text { scree (ha) }\end{array}$ & $\begin{array}{l}\text { Area of } \\
\text { mangrove (ha) }\end{array}$ & $\begin{array}{l}\text { Number and size of } \\
\text { mangrove patches }\end{array}$ \\
\hline Adolphus & 0 & 270.2 & large, close \\
\hline Augustus & 17878 & 31 & 4 small distant \\
\hline Bigge & 16113 & 109.1 & 7 small, distant \\
\hline Boongaree & 3992 & 278.6 & 2 large distant, 4 small \\
\hline Byam Martin & 221 & 0.0 & none \\
\hline Coronation & 0 & 80.7 & large, close \\
\hline Hidden & 1871 & 115.2 & 1 large, but distant \\
\hline Jungulu & 4803 & 25.7 & 1 large distant, 2 small \\
\hline Katers & 1571 & 5.1 & small \\
\hline Kingfisher & 0 & 204.9 & large, close \\
\hline Lachlan & 1112 & 74.3 & 1 large distant, 2 small \\
\hline Long & 1125 & 132.5 & large, close \\
\hline Mary & 0 & 55.1 & large, close \\
\hline Middle Osborn & 304 & 31.7 & 6 small distant \\
\hline NW Molema & 149 & 58.0 & large, close \\
\hline St Andrew & 216 & 38.2 & large close \\
\hline Sir Graham Moore & 0 & 7.0 & large, close \\
\hline Storr & 1883 & 140.9 & 1 large, but distant \\
\hline Sunday & 1170 & 350.2 & large, close \\
\hline South West Osborn & 371 & 6.0 & small \\
\hline Un-named & 11 & 23.5 & large, close \\
\hline Uwins & 3219 & 9.0 & small \\
\hline Wargul Wargul & 0 & 1.0 & small \\
\hline Wulalam & 0 & 251.9 & large, close \\
\hline
\end{tabular}


